\title{
A Chemotaxis-Like Pathway of Azorhizobium caulinodans Controls Flagella-Driven Motility, Which Regulates Biofilm Formation, Exopolysaccharide Biosynthesis, and Competitive Nodulation
}

\author{
Wei Liu, ${ }^{1}$ Yu Sun, ${ }^{1}$ Rimin Shen, ${ }^{1,2}$ Xiaoxiao Dang, ${ }^{1}$ Xiaolin Liu, ${ }^{1}$ Fu Sui, ${ }^{1}$ Yan Li, ${ }^{1}$ Zhenpeng Zhang, ${ }^{1}$ \\ Gladys Alexandre, ${ }^{3}$ Claudine Elmerich, ${ }^{4}$ and Zhihong $\mathbf{X i e}{ }^{1, \dagger}$ \\ ${ }^{1}$ Key Laboratory of Coastal Biology and Bioresource Utilization, Yantai Institute of Coastal Zone Research, Chinese Academy of \\ Sciences, Yantai, China; ${ }^{2}$ Shanxi Agricultural University, Taigu, Shanxi, China; ${ }^{3}$ Biochemistry, Cellular and Molecular Biology \\ Department, University of Tennessee, Knoxville, U.S.A.; and ${ }^{4}$ Institut Pasteur, Paris, France
}

Accepted 7 February 2018.

\begin{abstract}
The genome of the Azorhizobium caulinodans ORS571 contains a unique chemotaxis gene cluster (che) including five chemotaxis genes: $\operatorname{che} A, \operatorname{ch} W W, \operatorname{che} Y_{1}, \operatorname{cheB}$, and $\operatorname{che}$. Analysis of the role of the chemotaxis cluster of $A$. caulinodans using deletion mutant strains revealed that CheA or the Che signaling pathway controls chemotaxis behavior and flagella-driven motility and plays important roles in formation of biofilms and production of extracellular polysaccharides (EPS). Furthermore, the deletion mutants $(\Delta c h e A$ and $\Delta c h e A-R)$ were defective in competitive adsorption and colonization on the root surface of host plants. In addition, a functional CheA or Che pathway promoted competitive nodulation on roots and stems. Interestingly, a nonflagellated mutant, $\Delta$ fliM, displayed a phenotype highly similar to that of the $\Delta c h e A$ or $\Delta c h e A-R$ mutant strains. These findings suggest that through controlling flagella-driven motility behavior, the chemotaxis signaling pathway in A. caulinodans coordinates biofilm formation, EPS, and competitive colonization and nodulation.
\end{abstract}

Nitrogen-fixing bacteria are generally divided into two major classes, free-living and symbiotic. Symbiosis between rhizobia and hosts generally leads to formation of nodules on roots. Some members of legumes are also able to develop stem nodules (James et al. 2001; Tsien et al. 1983). Azorhizobium caulinodans ORS571 has the capability of fixing nitrogen both in the free-living and under symbiotic conditions with its host

${ }^{\dagger}$ Corresponding author: Zhihong Xie; E-mail: zhxie@yic.ac.cn

Funding: This work is financed by the Natural Science Foundation of Shandong Province (ZR2016CB44), National Natural Science Foundation of China (31570063 and 31600009), One Hundred-Talent Plan of Chinese Academy of Sciences (CAS), the High-Tech Industrialization Cooperation Funds of Jilin province and the Chinese Academy of Science (2017SYHZ0007), the Mechanisms of marginal land productivity expansion and technologies of storing grain in land (KFZD-SW-112) Shandong Key Research and Development Program (2016CYJS05A01-1, 2017GSF17129), Shandong Key Scientific and Technological Innovation Program (2017CXGC0303). Work in the Alexandre laboratory is supported by NSF-MCB 1330344. This study was conducted with the support of the Institute Pasteur, Paris, France.

*The $e$-Xtra logo stands for "electronic extra" and indicates that three supplementary movies are published online.

(C) 2018 The American Phytopathological Society
Sesbania rostrata (Dreyfus et al. 1983). In addition, it retains a capacity to induce nodule formation on roots as well as on stems of $S$. rostrata under symbiotic conditions (Dreyfus et al. 1983, 1988; Tsien et al. 1983).

The formation of biofilms on the root surface promotes colonization in many plant-associated bacteria, including genera such as Rhizobium, Gluconacetobacter, and Azospirillum (Rinaudi and Giordano 2010; Siuti et al. 2011; Yaryura et al. 2008). Furthermore, rhizobial extracellular polysaccharides (EPS) have been proposed to play important roles in adhesion and colonization of root surfaces (Burdman et al. 2000; Matthysse et al. 2005; Michiels et al. 1991; Santaella et al. 2008), formation of biofilms on roots during nodulation (Bianciotto et al. 2001; Fraysse et al. 2003; Fujishige et al. 2006; Meneses et al. 2011; Ramey et al. 2004; Rinaudi and Giordano 2010; Skorupska et al. 2006). Mutants with altered EPS are defective in symbiosis with host plants (Cheng and Walker 1998; Doherty et al. 1988; Wells et al. 2007). In soil bacteria, chemotaxis and motility favor the chemical or physical interaction with host roots and occupation of infection sites resulting in more competitive colonization and nodulation ability (Caetano-Anollés et al. 1988; Greer-Phillips et al. 2004; Miller et al. 2007; Van de Broek and Vanderleyden 1995).

Bacterial chemotaxis is a motility-based response initiated by perception of environmental chemical signals. The chemotaxis signal transduction pathway has been best studied in Escherichia coli (Wadhams and Armitage 2004). This pathway is comprised of conserved proteins that include a histidine kinase CheA, an adaptor protein $\mathrm{CheW}$, a response regulator $\mathrm{CheY}$, a methylesterase CheB, a methyltransferase CheR, and multiple chemoreceptors. CheA acts as the central processing unit of this system. Environmental signals sensed by chemoreceptors regulate the phosphorylated state of CheA via CheW. The phosphoryl group is then transferred from CheA to CheY, resulting in phosphorylated CheY. Phospho-CheY then binds proteins in the flagellar motor switch complex (comprised of FliM, FliN, and FliG) to affect flagellar rotational direction (Stock and Surette 1996).

Generally, the basic molecular mechanism of chemotaxis is conserved in bacteria (Wuichet and Zhulin 2010). There is only a single chemotaxis operon in the E. coli genome. However, many motile soil bacteria possess two or more chemotaxis operons encoding homologs of the $E$. coli chemotaxis proteins in their genomes (Scharf et al. 2016; Szurmant and Ordal 2004). Furthermore, gene order and composition of operons vary within members of the $\alpha$-proteobacteria. Chemotaxis operons in some 
proteobacterial species were reported to regulate chemotaxis response, flagellar synthesis, cell size, cyst formation, biofilms formation, or other cellular functions (Berleman and Bauer 2005; Bible et al. 2008; D’Argenio et al. 2002; Ferrández et al. 2002; Kirby and Zusman 2003; Vlamakis et al. 2004). There are two chemotaxis operons in the genome of Sinorhizobium meliloti (which is a synonym of the accepted name Ensifer meliloti) and the chemotactic response is controlled by the Che1 pathway (Meier et al. 2007; Sourjik and Schmitt 1996). In Azospirillum brasilense, there are four main sets of chemotaxis gene clusters encoded within the genome (WisniewskiDyé et al. 2011). Che1 signaling pathway controls swimming speed and has a minor role in chemotaxis (Bible et al. 2012), while Che4 controls changes in swimming direction and competitive colonization on plant root surfaces (Mukherjee et al. 2016).

A. caulinodans ORS571 are motile soil bacteria that have versatile rhizobial lifestyles. Analysis of available genome sequence (Lee et al. 2008) indicates that A. caulinodans relies on a single chemotaxis system in the whole genome (Jiang et al. 2016b). The chemotaxis system (che) contains five chemotaxis genes, cheA, cheW, che $Y_{1}$, cheB, and cheR, hereafter called che $A W Y_{1} B R$, transcribed in the same direction, from a putative $\sigma 54$-dependent promoter upstream of cheA (Jiang et al. 2016b). While the function of some chemoreceptors has been investigated (Jiang et al. 2016a; Liu et al. 2017a), the role of signaling mediated by the products of the chemotaxis cluster (che) in A. caulinodans ORS571 has not yet been established. Our results show that the che cluster of A. caulinodans ORS571 regulates directional motility and other cellular functions in a free-living state or in symbiosis with its host $S$. rostrata. We provide evidence that che-mediated regulation of other cellular functions depends on functional flagella-driven motility.

\section{RESULTS}

Chemotaxis system of $A$. caulinodans ORS571.

Analysis of the A. caulinodans ORS571 genome (Lee et al. 2008) revealed a large DNA region (AZC_0620 to AZC_0666), spanning about $45 \mathrm{~kb}$, that contains open reading frames (ORFs) whose translation products shared similarity with proteins involved in synthesis of flagella and chemotaxis response (Fig. 1A). A preliminary comparative analysis identified a group of five che genes (AZC_0661 to AZC_0665), che $A W Y_{1} B R$, transcribed in the same direction (Fig. 1A). In this gene cluster, translational overlapping is manifest between the cheA and cheW, between $c h e Y_{1}$ and $c h e B$, and between $c h e B$ and $c h e R$ and, given that chemotaxis proteins are typically organized as operons, it is assumed that the five genes here are also organized as a single transcription unit. A gene (AZC_0660) named tlpA1, encoding a transmembrane methyl-accepting chemotaxis protein (MCP) product (Liu et al. 2017a), is located 200 nucleotides upstream of cheA (Fig. 1A). Another mcp gene (AZC_0666), also encoding a transmembrane MCP product, is located downstream of the che cluster (Fig. 1A). The icpB gene (AZC_3718) encoding a soluble chemotaxis receptor previously characterized is not linked to the cluster (Jiang et al. 2016a). Two other chemotaxis genes $c h e Y_{2}$ (AZC_0620) and cheZ (AZC_0621), are located in the distal region of the che gene cluster and are predicted to be transcribed divergently. A flagella-related gene cluster (AZC_0625 to AZC_0655) containing fliM (AZC_0643) is encoded between the two chemotaxis genes (che $Y_{2}$ and cheZ) and the che gene cluster (Fig. 1A). This favors the hypothesis that the che gene cluster encodes a chemotaxis pathway that controls flagella-mediated motility. Furthermore, using transmission electron microscopy, it was found that $A$. caulinodans ORS571 cells possess one to three flagella when grown in liquid medium (Fig. 1B).

\section{A che cluster controls chemotaxis response} of A. caulinodans ORS571.

To determine the role of the che cluster in the chemotactic response of $A$. caulinodans ORS571, we constructed two mutant strains (discussed below). The $\Delta c h e A$ mutant is carrying a complete deletion of the cheA gene, while a second mutant carries a deletion of the che cluster spanning che $A W Y_{1} B R$ and is referred to as $\Delta c h e A-R$. Both mutants displayed a wild-type flagellation pattern (Fig. 1C and D), while, as expected, a mutant strain carrying a deletion of the fliM gene $(\Delta f l i M)$ encoding one of three components of the flagella motor's switch complex was devoid of flagella (Fig. 1E). Chemotaxis behavior of these mutant strains was compared with that of the wild type in soft agar plate assay with carbon sources previously identified as chemoeffectors for A. caulinodans ORS571 (Jiang et al. 2016a). In the presence of succinate, lactate, or proline as the sole carbon source and chemoeffector, the $\Delta c h e A$ and $\Delta c h e A-R$ mutant strains expanded from the point of inoculation and formed chemotactic rings that were significantly reduced in size, compared with the wild type, regardless of whether they grew under nitrogen-fixation conditions or with combined nitrogen available (Fig. 2A and B). The chemotaxis defect of the $\Delta c h e A$ mutant strain was rescued by introduction of a plasmid carrying the wild type $c h e A$ gene into the $\triangle c h e A$ mutant ( $\triangle c h e A-\mathrm{com})$ (Fig. $2 \mathrm{~A}$ and $\mathrm{B}$ ). Moreover, the chemotaxis pattern displayed by the $\triangle c h e A$ and $\Delta c h e A-R$ mutants in this assay was similar to that of $\Delta f l i M$, which is a nonmotile mutant strain. These results suggest that the che cluster plays an essential role in chemotaxis of A. caulinodans ORS571.

To rule out the possibility that the reduced chemotactic ring diameter of the mutants were linked to a defect in bacterial growth, growth rates of each strain was determined in L3 medium $\left(10 \mathrm{mM}\right.$ succinate as carbon source and $10 \mathrm{mM} \mathrm{NH}_{4} \mathrm{Cl}$ as nitrogen source). The results show that the growth rate of mutants is similar to that of the wild type (Fig. 3A). Furthermore, since the che $A$ gene is located directly upstream of the cheWY $B R$ cluster and is transcribed in the same direction (Fig. 1A), we determined whether deletion of cheA affected che $W Y_{1} B R$ gene expression by comparing the expression of these genes in the wild type, $\Delta c h e A$, and $\Delta c h e A-R$ strains and, as expected, found similar expression profiles of $c h e W Y_{1} B R$ genes in the wild type and $\triangle c h e A$ (Fig. 3B). These data suggest that the diminished diameters observed on swim plate assays are related to defects in chemotaxis response.

To further assess chemotaxis behavior of these mutants, competitive quantitative capillary assays were conducted, using bacterial suspensions containing equal ratios of the wild type and each of these mutants, respectively. Figure 4 shows data obtained with capillary tubes filled with buffer, succinate, or sodium lactate as the attractants. Determination of the number of bacterial cells in capillary tubes filled only with buffer revealed an excess of the wild type as compared with the $\Delta c h e A, \Delta c h e A-R$, or $\Delta f l i M$ (Fig. 4), suggesting that the swimming motility bias of the mutant cells was impaired. Furthermore, when the capillary tubes were filled with succinate or sodium lactate, the number of the $\Delta$ cheA, $\Delta$ cheA-R, or $\Delta f l i M$ mutant cells was also significantly reduced compared with the wild type under similar conditions (Fig. 4). These results confirmed that the $\Delta c h e A$ and $\Delta c h e A-R$ mutants are impaired in cell chemotaxis response and motility behavior.

\section{Involvement of the cheA and che cluster in the control of flagella-driven motility behavior.}

Chemotaxis ultimately controls the probability of change in the swimming direction or swimming motility bias. Chemotaxis mutants are thus expected to display change in the swimming motility bias compared with parent strain. The freeswimming behavior of the wild type and the mutant strains were analyzed by motion tracking. The swimming paths of the 
wild-type cells showed their swimming as long runs alternating with sudden direction changes (turns) (Supplementary Movie S1). In contrast, the $\triangle c h e A$ (Supplementary Movie S2) and $\Delta$ cheA-R (Supplementary Movie S3) mutants swam with incessant changes in the swimming direction (tumbles). The nonmotile mutant $\Delta f l i M$ was used as a control (data not shown). The motility patterns indicate that chemotaxis signaling in A. caulinodans ORS571 regulates the probability of change in swimming direction and that the unique Che pathway, through $\mathrm{CheA}$, is the major regulator of this behavior.
The $\Delta c h e A$ and $\Delta c h e A-R$ mutants affect biofilm formation.

Motility and chemotaxis play important roles in attachment and biofilm formation under static conditions, with the swimming bias being an important trait controlling this behavior (Merritt et al. 2007). The relative biofilm production ability of the wild type and che mutant was compared using crystal violet staining (Fig. 5A). Quantitative data further confirmed that the decrease in staining observed with the mutant strains correlated with a decrease in biofilm mass compared with the wild type

A

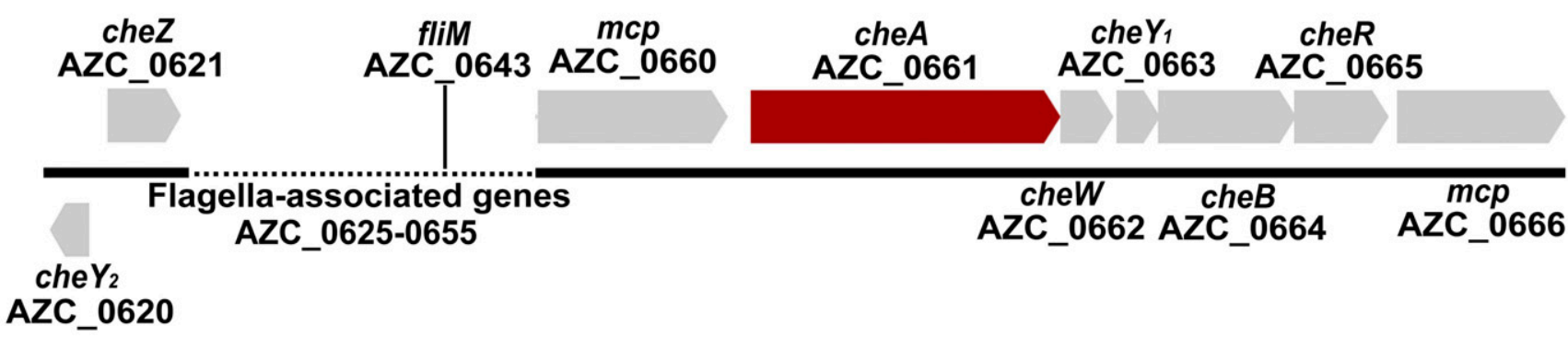

B

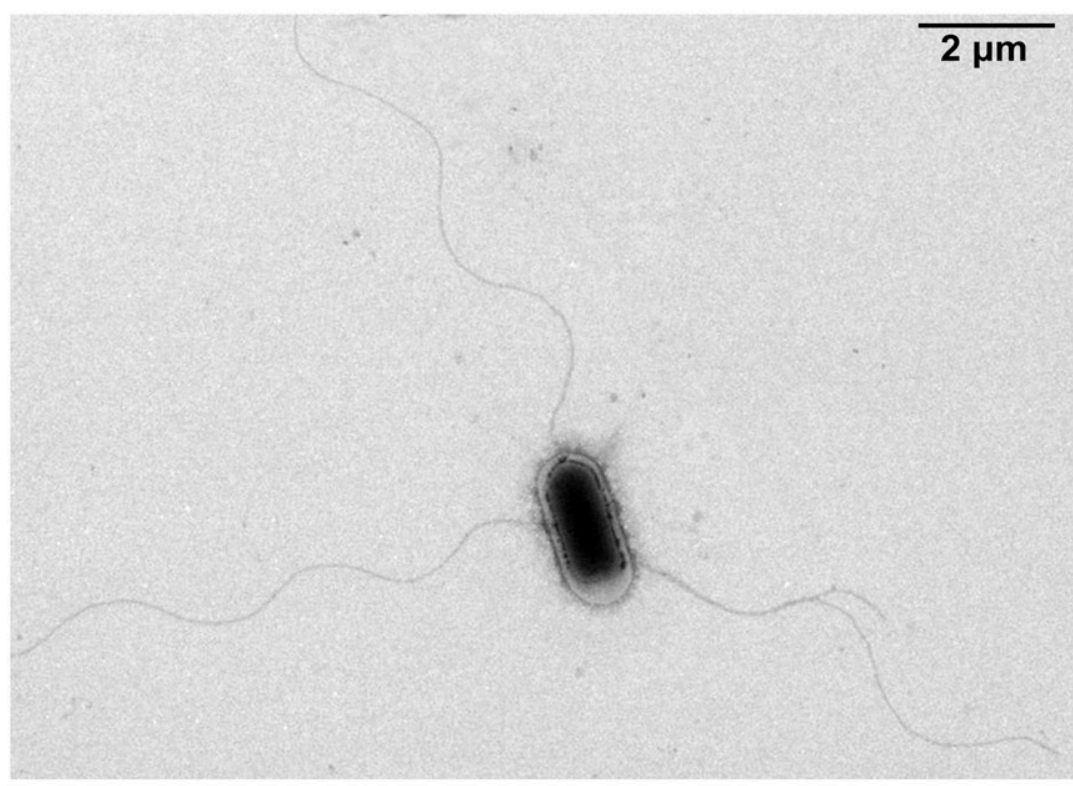

C

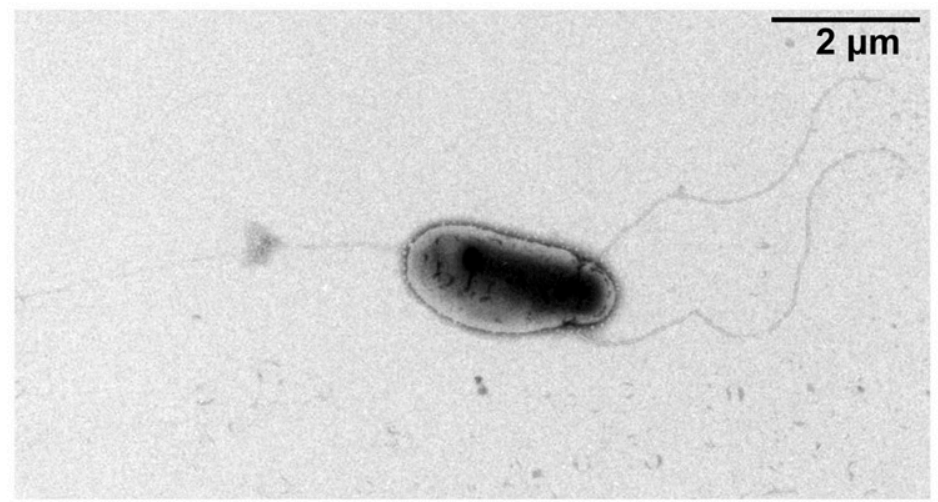

D

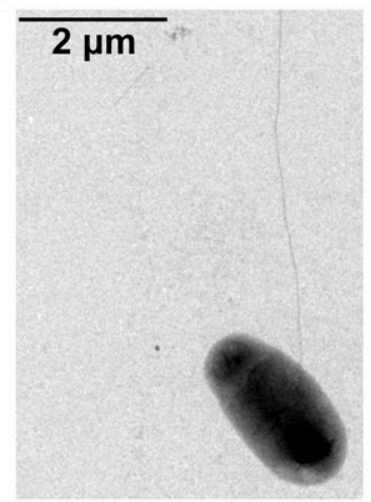

$\mathbf{E}$

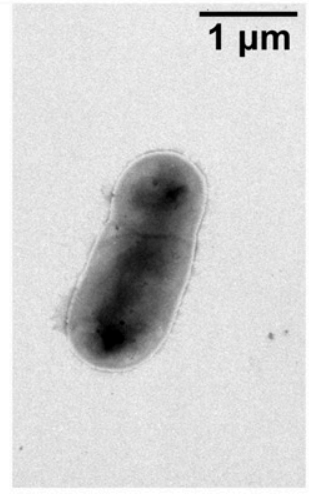

Fig. 1. Chemotaxis-related genes encoded within the Azorhizobium caulinodans ORS571 genome and flagellation pattern. A, Organization of chemotaxisrelated genes of A. caulinodans ORS571. The arrows indicate the direction of transcription of open reading frames and are drawn relative to scale. B, Transmission electron micrographs of A. caulinodans ORS571 showing one to three flagella. Cells were negatively stained with phosphotungstic acid. Bar, $2 \mu \mathrm{m}$. C, Transmission electron micrographs showing the presence of flagella for the $\Delta$ cheA-R and $\mathbf{D}, \Delta c h e A$ mutant strains and $\mathbf{E}$, the absence of flagella for the $\Delta$ flim mutant. 
(Fig. 5B). To further distinguish the possible roles of motility or chemotaxis in biofilm formation, the nonmotility mutant $\Delta$ fliM was also analyzed for its ability to form biofilms and was found to be defective compared with the wild type. These data indicate that the Che signaling pathway modulates biofilm formation, probably through its effect on cell flagella-driven motility.

\section{The $\Delta c h e A$ and $\Delta c h e A-R$ mutants impaired}

\section{in biosynthesis of EPS.}

EPS are known as key matrix components involved in the process of biofilm formation by bacteria (Ryder et al. 2007; Watnick and Kolter 2000). Thus, EPS production by the $\Delta c h e A$ and $\Delta c h e A-R$ mutants was compared with that of the wild type. The quantitative results showed that the $\Delta c h e A$ and $\Delta c h e A-R$ mutants produced less total EPS than the wild type under all tested conditions. Interestingly, the $\Delta f l i M$ mutant was also defective in EPS production (Fig. 6). Taken together, these data indicate that chemotaxis signaling via che and flagellar motility modulates EPS production, with this phenotype likely also contributing to the reduced biofilm formation.

\section{The che cluster is essential}

\section{for adsorption and colonization on roots.}

Quantitative assays were used to analyze the adsorption and colonization ability of the different strains on the root surfaces to document the role of the che cluster in the symbiotic association with the host plant $S$. rostrata. We used a competitive assay to compare the adsorption ability of the mutants and wild type. Surface-sterilized seedlings were co-inoculated with the wild type and mutants at an approximate $1: 1$ ratio for $4 \mathrm{~h}$. Results indicate that the $\triangle c h e A$ and $\Delta c h e A-R$ mutants were significantly impaired in their absorption to $S$. rostrata roots
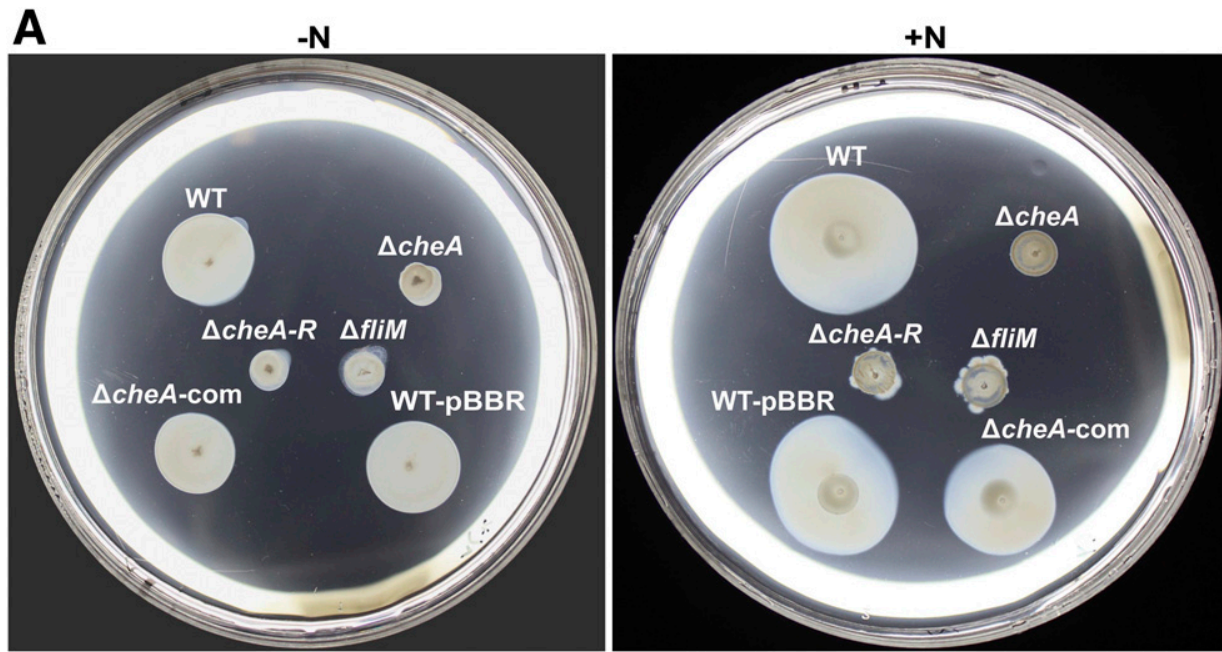

B

$\%$ Wild type diameter

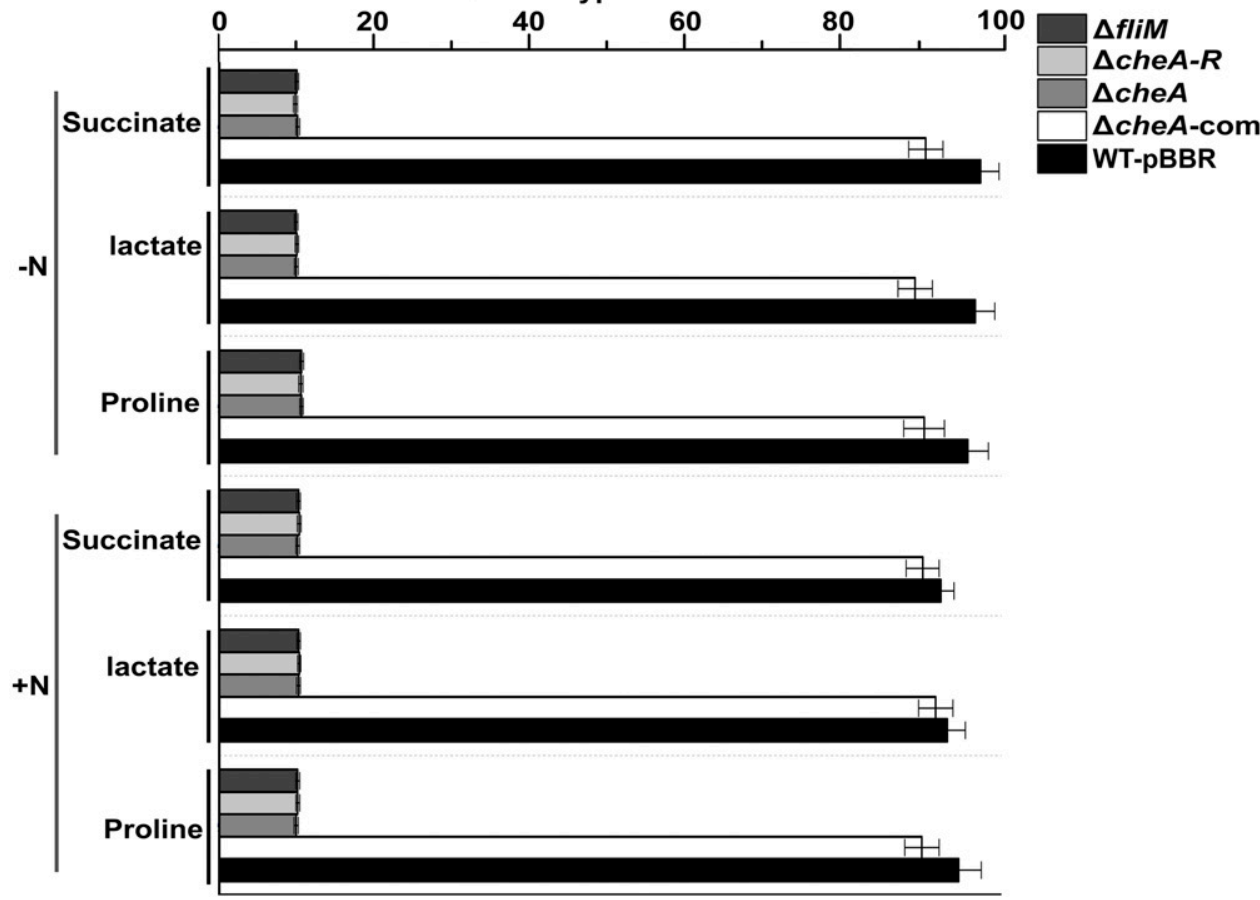

Fig. 2. Chemotaxis behavior of the ORS571 wild type and mutant strains $\Delta c h e A-R$ and $\Delta c h e A$, the complementation strain $\Delta c h e A$-com, and the $\Delta f l i M$ mutant toward attractants on soft agar plates. Carbon sources and nitrogen source were included at a final concentration of $10 \mathrm{mM}$. A, Representative L3 plates with succinate as the sole carbon source. B, The average diameters of mutants are expressed relative to that of wild type (taken as 100\%). Error bars represent standard deviations of mean from three repetitions. 
compared with the wild type, whereas the complementation strain $(\Delta c h e A$-com) could restore the phenotype of $\Delta c h e A$. In addition, we found that the absorption ability of the $\Delta$ fliM mutant was also severely impaired (Fig. 7A).

We further hypothesized that the lack of adsorption to roots should result in a defective colonization by the $\Delta c h e A$ and $\Delta c h e A-R$ mutants. First, to establish an overall colonization pattern, a quantitative assay was used to compare the competitive colonization ability of the wild type and the mutants. Three-day-old seedlings were co-inoculated with the wild type and mutants at a 1:1 ratio for 7 days. Colonization efficiency was determined by counting the number of cells re-isolated from the root surfaces at the end of the incubation period. As expected, the number of cells of the $\Delta c h e A$ and $\Delta c h e A-R$ mutants recovered from the root surface was significantly reduced compared with wild-type cells. However, the wild-type phenotype could be restored in the complementation strain $\Delta c h e A-$ com. Similarly, the $\Delta f l i M$ mutant deficient in flagella was shown to be less competitive in colonization of the host (Fig. 7B). Given that both the $\Delta c h e A$ and $\Delta c h e A-R$ mutants as well as the nonflagellated $\triangle f l i M$ mutant are severely impaired in adsorption and surface colonization of $S$. rostrata roots, this suggests that the Che signaling pathway contributes to root symbiosis through regulating flagella-based motility.

\section{The Che pathway modulates} competitive nodule formation.

Surface colonization is essential for effective symbiotic nodulation of Sesbania spp. (Mitra et al. 2016). To further test whether the chemotaxis mutants have any symbiotic nodulation defects, the nodule formation ability was used to compare between the wild type and mutants. When inoculated alone on stems or roots of S. rostrata, the $\Delta c h e A$ and $\Delta c h e A-R$ mutants formed normal stem (Fig. 8A) or root nodules (Fig. 8B), with
A

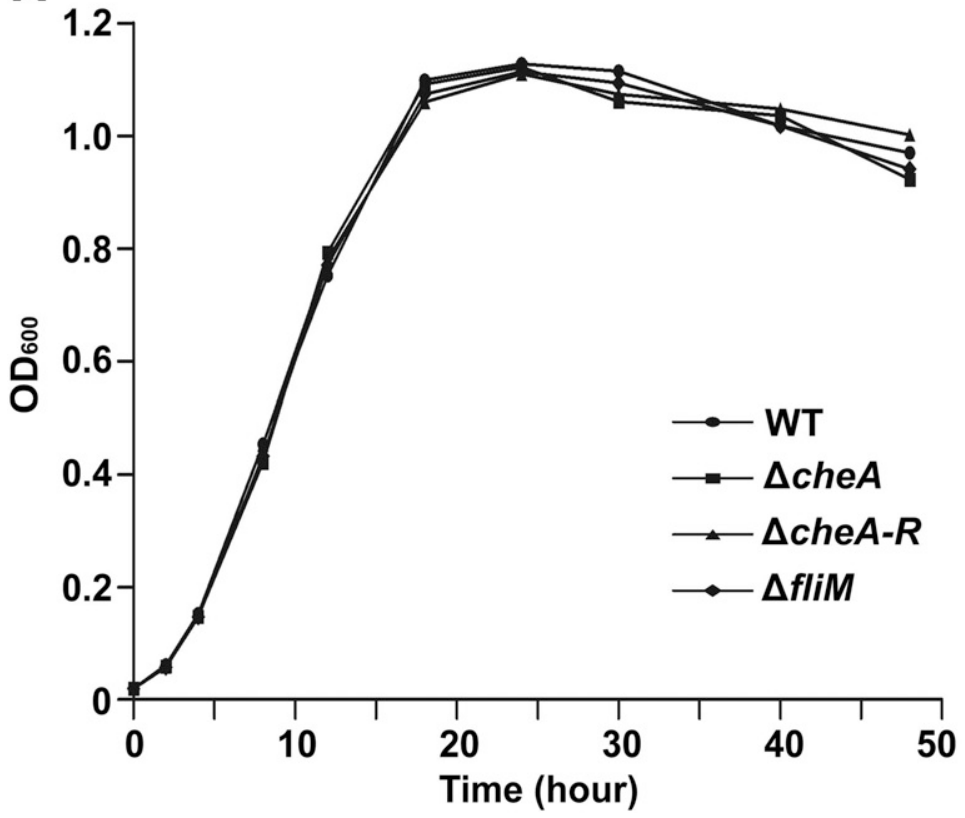

B

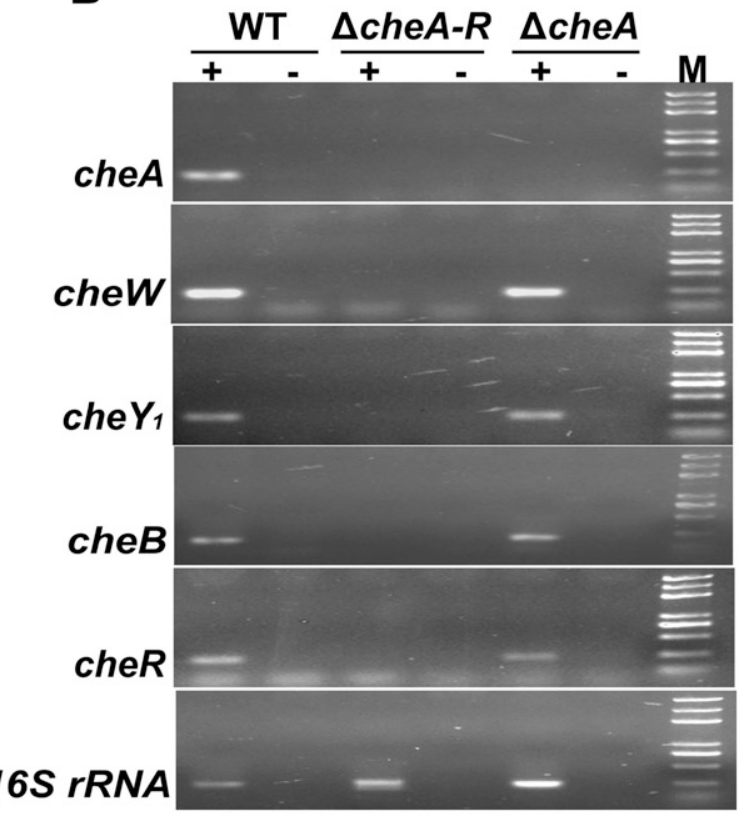

Fig. 3. Growth of ORS571 and mutant strains and gene expression. A, Growth curves of the wild type (WT), $\Delta c h e A-R, \Delta c h e A$, and $\Delta f l i M$ in L3 medium. B, Expression of $c h e W Y_{1} B R$ genes in the wild-type (ORS571) and chemotaxis mutants. The che $W Y_{1} B R$ gene expression was detected by polymerase chain reaction using appropriate primers. The $16 S \mathrm{rRNA}$ gene was amplified as a positive gene control and the cheA gene was amplified as a negative gene control. + indicates samples incubated with reverse transcription and - indicates samples with no reverse transcription.

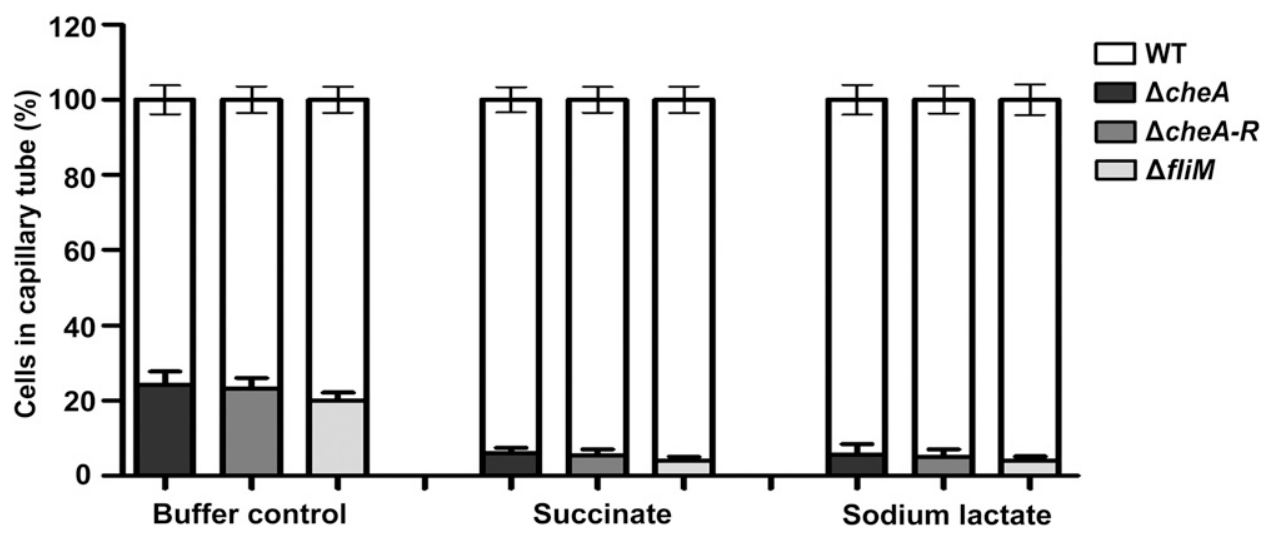

Fig. 4. Competitive quantitative capillary chemotaxis assays of the ORS571 wild type, $\Delta c h e A, \Delta c h e A-R$, and $\Delta$ fliM mutants. The capillary tubes filled with chemotaxis buffer (left), $10 \mathrm{mM}$ succinate (middle), or sodium lactate (right) as the carbon source were then inserted into the 96 -well plate containing the bacterial suspension (mutants and wild type 1:1 ratio). Each datapoint represents the mean of three independent experiments and the error bars represent the standard error of the mean. 
no obvious difference in the morphology, compared with the wild type. Further, the competitive nodulation ability on stems and roots was used to compare between the wild type and $\Delta c h e A$ or $\Delta c h e A-R$ or $\Delta f l i M$ mutants. All these mutants were severely defective in the ability to compete for nodulation of root and stem compared with the wild type (Fig. 8C). Together, these results demonstrate that Che pathway-mediated flagella motility is important for promoting competitive nodule formation.

\section{DISCUSSION}

Many motile soil bacteria possess multiple chemotaxis operons playing pleiotropic roles in regulating flagella-mediated motility and other functions (Scharf et al. 2016). A. caulinodans is a motile, nitrogen-fixing soil bacterium with a preference for organic acids as carbon source (Dreyfus et al. 1988). There is a single chemotaxis gene cluster $\left(\right.$ che $\left.A W Y_{1} B R\right)$ (Fig. 1A) predicted from the genome sequence, but the DNA region containing this cluster contains other genes involved also in the chemotactic response, such as tlpAl (AZC_0660) (Liu et al. 2017a) and cheZ (AZC_0621) (Liu et al. 2017b). Here, we confirmed that the Che pathway (cheAWY ${ }_{1} \mathrm{BR}$ ) directly controls the cellular chemotaxis response and flagella-mediated motility behavior. A mutant lacking partial cheA (Liu et al. 2017a) does not yield a null chemotaxis phenotype in soft agar plates (data not shown), but there is no obvious difference in capillary tube chemotaxis assays and flagella motility behavior (Liu et al. 2017a) compared with $\triangle c h e A-R$ mutants. This is why, in the present work, the role of CheA was re-evaluated using a new construction carrying a complete deletion of the cheA gene $(\triangle c h e A)$. Indeed, the chemotaxis phenotype and motility behavior of the newly constructed $\Delta c h e A$ mutant is similar to that of the mutant strain carrying the complete deletion of the che cluster $\Delta c h e A-R$ (Fig. 2). This indicates that chemotaxis signaling in A. caulinodans ORS571 controls the chemotaxis response and flagella-driven motility and that the unique che cluster, through the unique $\mathrm{CheA}$, is the major regulator of these behaviors.

Che operons appear to regulate different cell functions in different bacteria (Berleman and Bauer 2005; D’Argenio et al.

A

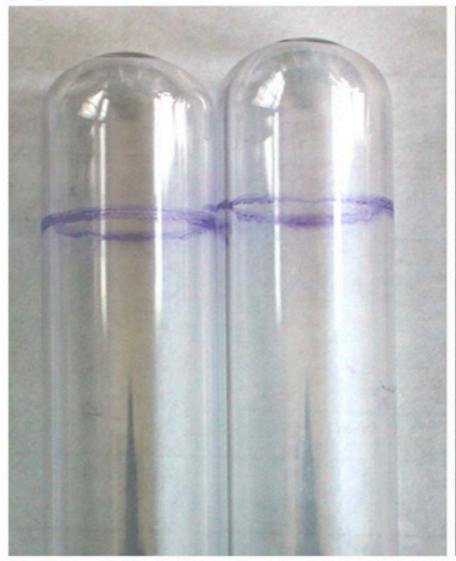

B

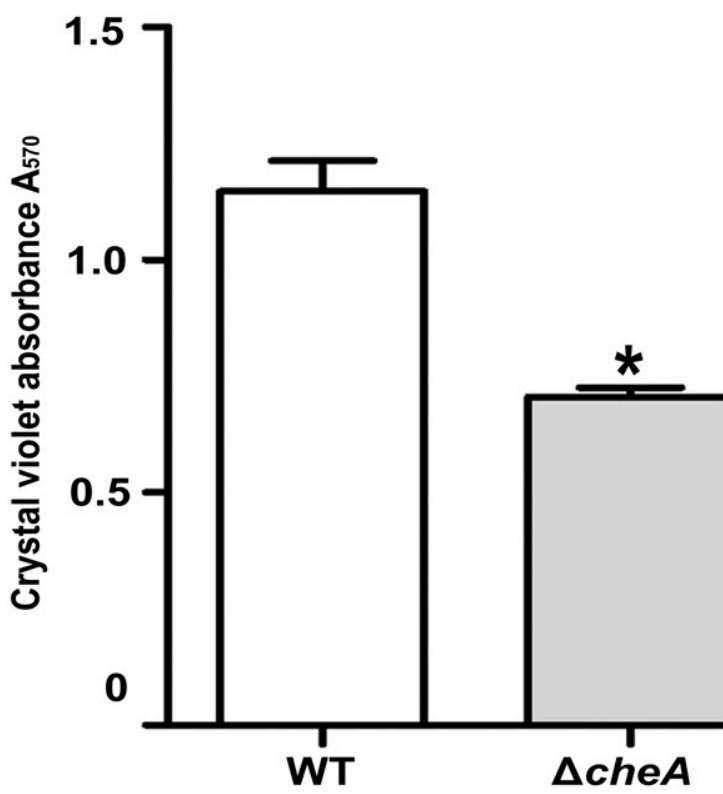

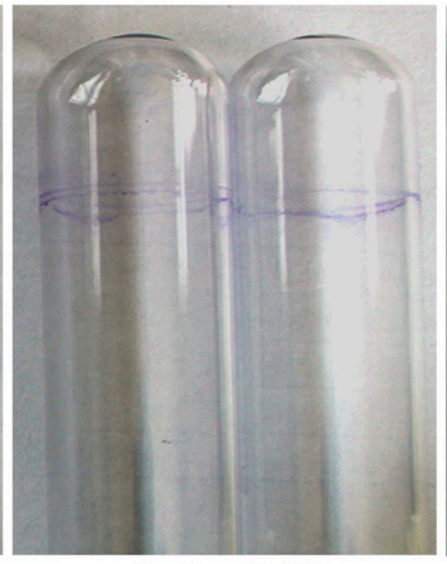

$\Delta c h e A-R$ $\Delta c h e A$

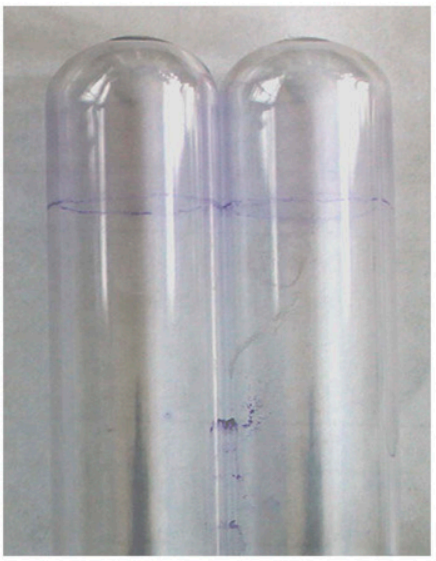

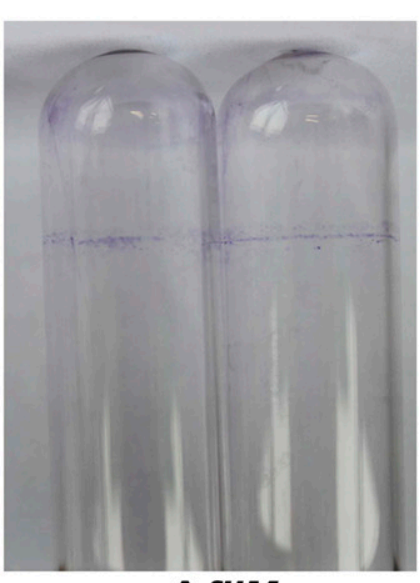

$\Delta$ flim

\section{政}


2002; Ferrández et al. 2002; Kirby and Zusman 2003; Vlamakis et al. 2004). In the Azospirillum genus, the Che1 pathway of Azospirillum brasilense also encodes a conserved set of CheAWYBR homologs controlling swimming speed during chemotaxis and regulating the cell size (Bible et al. 2008; Gullett et al. 2017). In addition, several che operon mutants of Azospirillum brasilense had an altered production of total EPS that affected colony morphology as well as clumping and flocculation behaviors (Bible et al. 2008). In the present work, the flocculation behavior showed no significant difference between wild type and mutants (data not shown). However, our data showed that defects in chemotaxis caused by mutation within che genes affected chemotaxis response as well as the total amount of EPS produced.

Interestingly, decreased EPS biosynthesis in the $\Delta$ fliM mutant is similar to that observed in the che mutants. Given that a nonflagellated mutant had a similar phenotype to nonchemotactic mutants, this suggests that the $\triangle c h e A-$ and $\triangle c h e A-R-$ reduced EPS production is likely indirectly related to chemotaxis behavior and, rather, is associated with flagella-driven motility. Several other genes involved in the chemotactic response in A. caulinodans were also shown to be involved in EPS production. In particular, a mutation of the $i c p B$ gene, encoding a soluble chemoreceptor and mutation of the cheZ-like gene, led to increased EPS production (Jiang et al. 2016a, Liu et al. 2017b) suggesting their involvement in a negative regulation of EPS production, while the Che pathway and FliM would be involved in a positive regulation of EPS.

The decreased EPS production of $\triangle c h e A$ and $\triangle c h e A-R$ and nonflagellated $(\triangle f l i M)$ mutant is correlated with decreased biofilm formation (Fig. 5), as also reported for a mutant of the

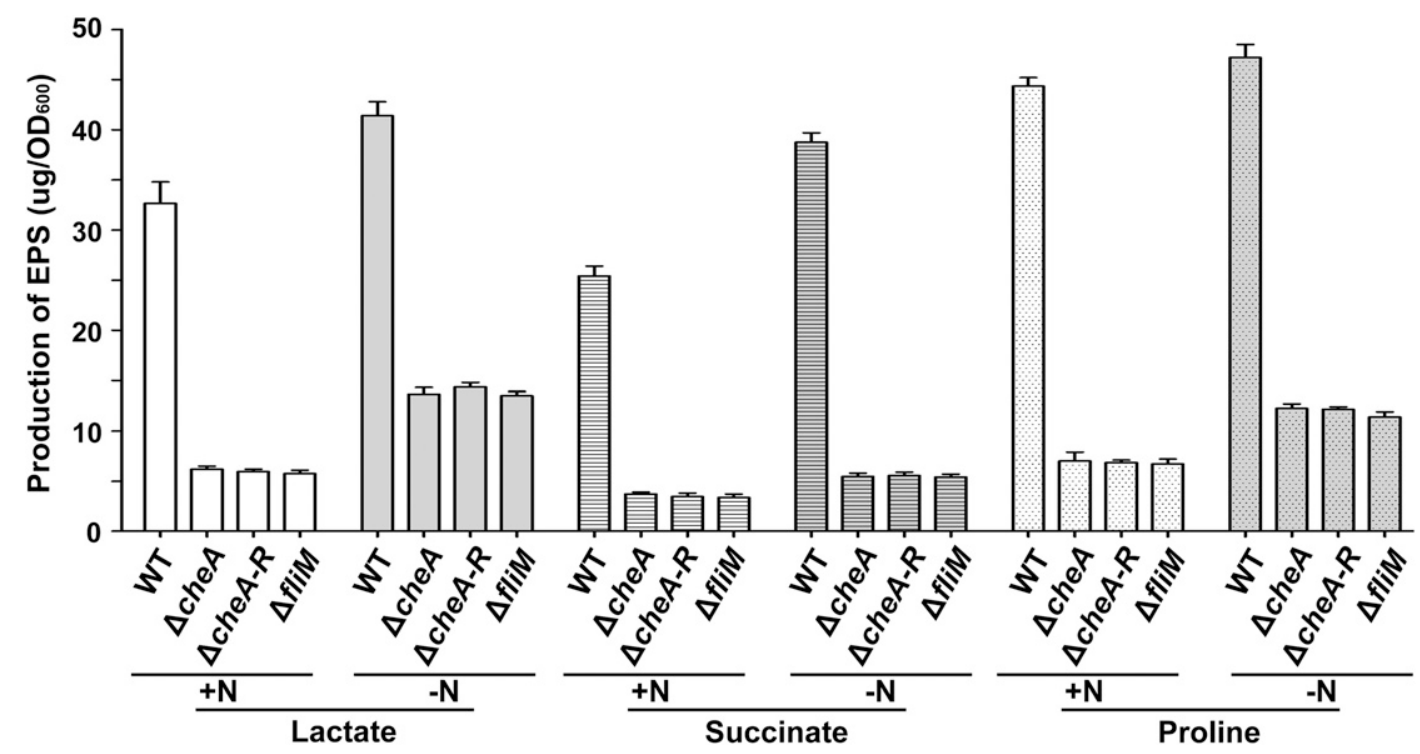

Fig. 6. Quantitative analysis of extracellular polysaccharide (EPS) production of the ORS571 wild type, $\Delta c h e A, \Delta c h e A-R$, and $\Delta f l i M$ on plates with different carbon sources. Error bars indicate standard deviations from the mean of three independent experiments.
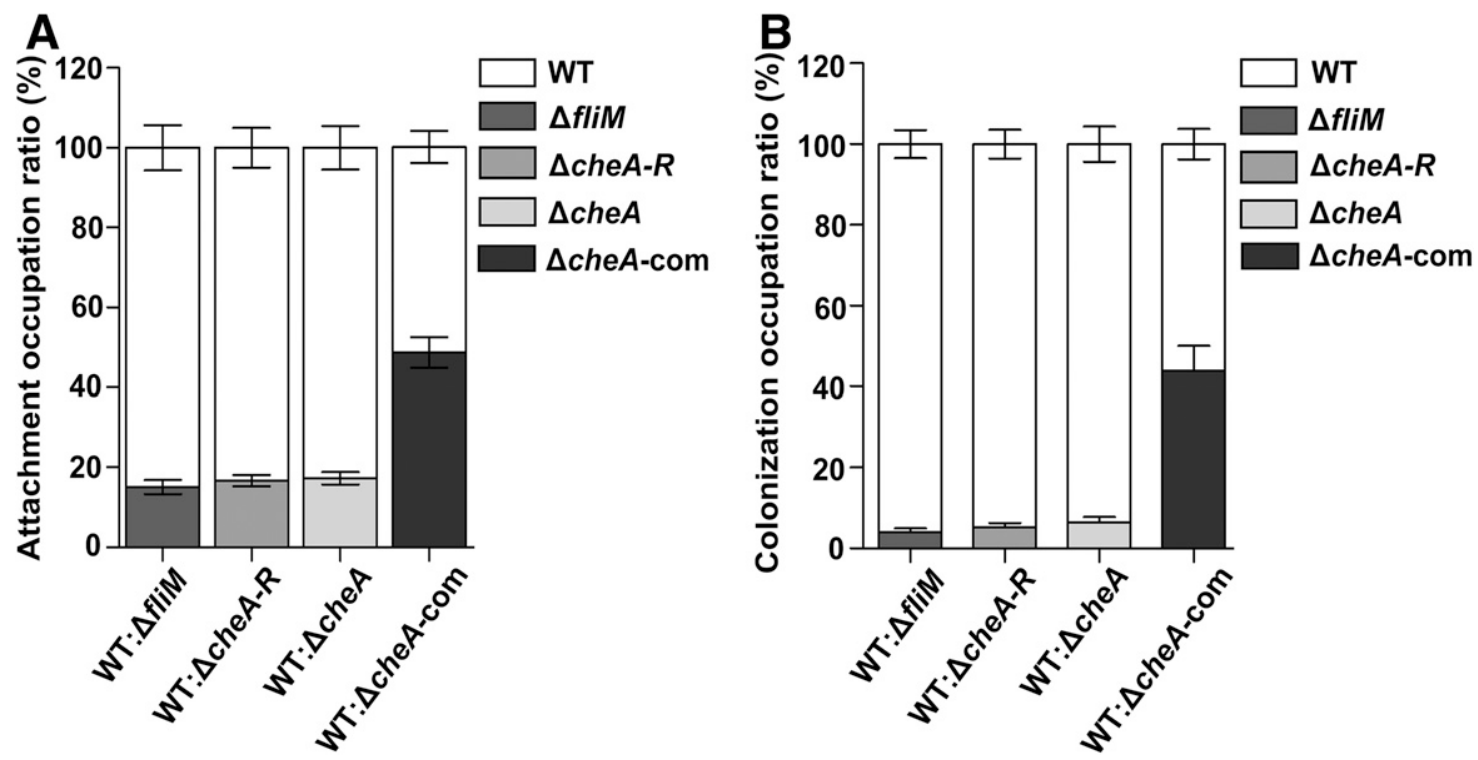

Fig. 7. Adsorption and colonization ability of the Azorhizobium caulinodans ORS571 wild type and chemotaxis mutant strains on Sesbania rostrata root surface. A, Competitive adsorption on $S$. rostrata roots with the wild type and either $\Delta c h e A, \Delta c h e A-R, \Delta f l i M$, or complementation strain $\Delta c h e A$-com in an approximate 1:1 ratio. B, Competitive colonization levels of $S$. rostrata roots with the wild type and either $\Delta$ cheA, $\Delta c h e A-R, \Delta f l i M$, or complementation strain $\Delta c h e A$-com in an approximate 1:1 ratio. The adsorption and colonization ratios were analyzed by polymerase chain reaction. Error bars represent standard errors of the mean calculated from three independent experiments. 
transmembrane chemoreceptor tlpA1 (Liu et al. 2017a), while, in contrast, the cheZ-like mutant strain displayed increased ability of biofilm formation. This suggests a complex regulatory network that needs to be further investigated. In E. coli, biofilm formation in $\Delta c h e A-Z$ (nonchemotactic) was similar to that of the wild type, and only the nonflagellated or paralyzed flagellated mutants were defective in formation of biofilms. This finding indicates bacterial motility but not chemotaxis is essential for biofilm formation in E. coli (Pratt and Kolter 1998), but the chemotaxis and its effect on the swimming-motility pattern appear to be important in biofilm formation by several soil bacteria, such as Azorhizobium caulinodans and Azospirillum brasilense but an exact mechanism is yet to be identified.
Previous research indicates that chemotaxis and motility can confer a significant advantage of bacterial competitiveness in the rhizosphere (Brencic and Winans 2005), colonization on plant roots (Bernabéu-Roda et al. 2015; Dekkers et al. 1998; de Weger et al. 1997; Miller et al. 2007; Simons et al. 1996; Van de Broek and Vanderleyden 1995; Van de Broek et al. 1998), and the efficiency of nodule initiation (Caetano-Anollés et al. 1988). In Sinorhizobium meliloti, several nonmotile or nonchemotatic mutants ( $c h e^{-}$, mot $^{-}$, and fla $^{-}$) were all less effective than the parent as competitors in root adsorption and nodulation, and motility and chemotaxis appear to be quantitatively important in root adsorption and nodule initiation (CaetanoAnollés et al. 1988). In Rhizobium leguminosarum, only the
A

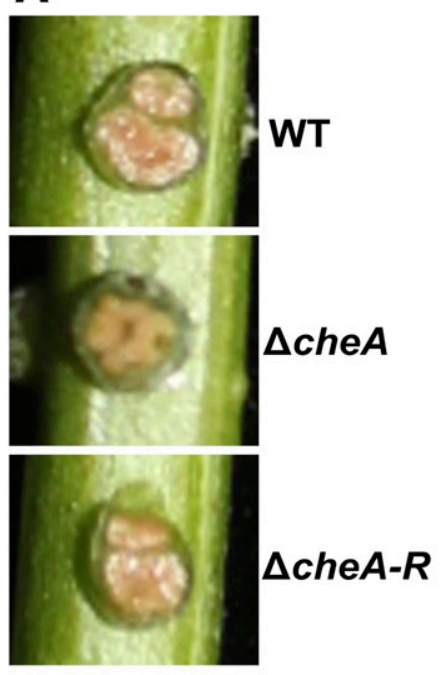

C

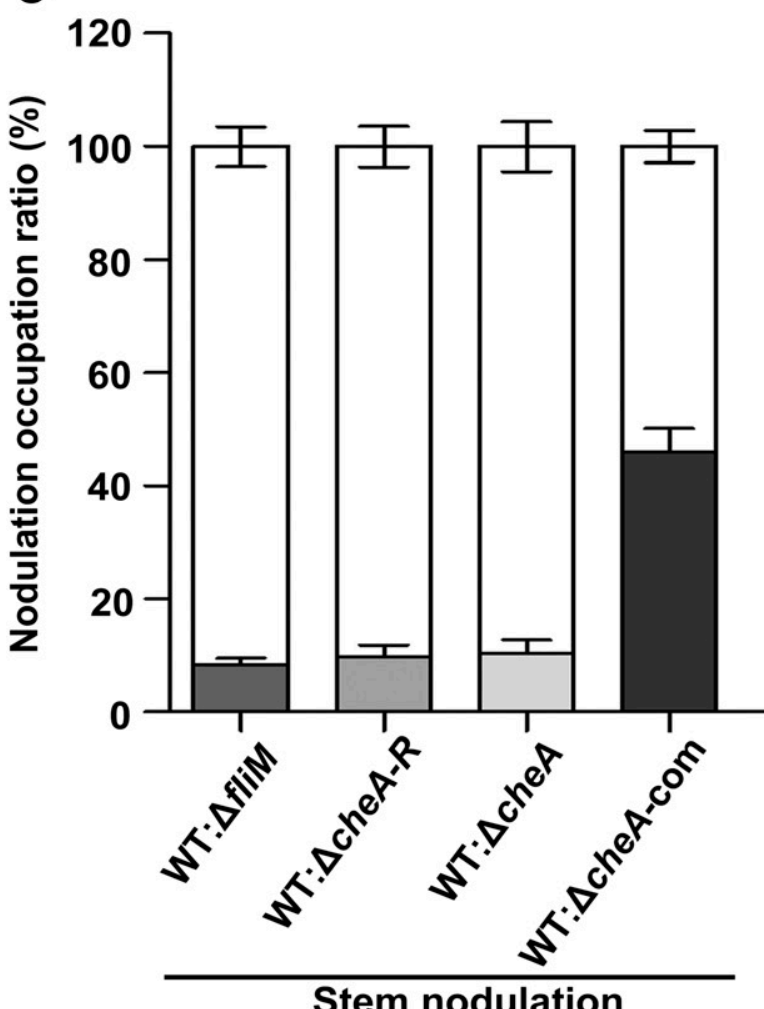

Stem nodulation
B

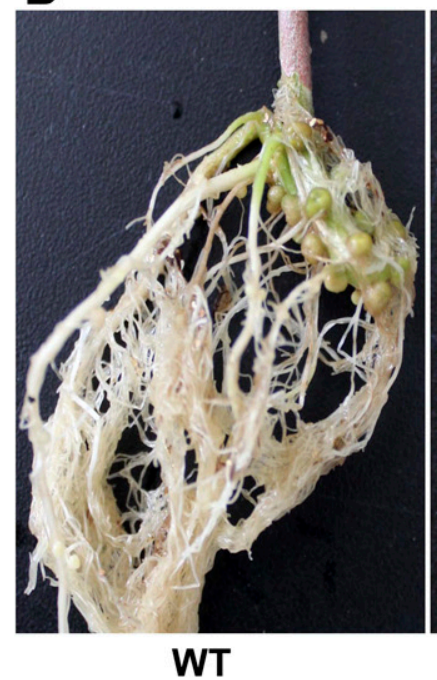

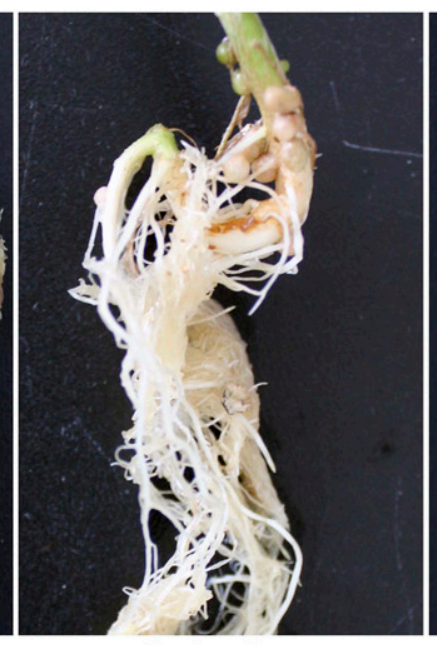

$\Delta c h e A$

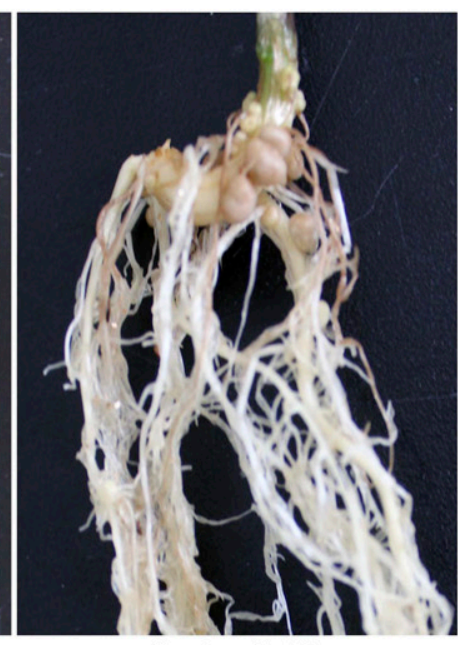

$\Delta c h e A-R$

Fig. 8. Nodulation tests between the Azorhizobium caulinodans ORS571 wild type and mutants. A, Stem nodules were induced by the wild type (WT), $\Delta$ cheA, and $\Delta c h e A-R$. Leghemoglobin of stem nodules shows characteristic orange-brown color. B, Root nodules induced by WT, $\Delta c h e A$, and $\Delta c h e A-R$ mutants. $\mathbf{C}$, Analysis of numbers of WT, $\Delta c h e A, \Delta c h e A-R, \Delta f l i M$, and complementation strain ( $\Delta c h e A$-com) nodules in a competitive nodulation assay on stems and roots. Error bars represent standard errors of the mean calculated from three independent experiments. 
chel cluster controls swimming motility bias and chemotaxis as well as competitive nodule formation, while the che 2 cluster that has a minor effect on chemotaxis is dispensable for competitive nodulation. In Azospirillum brasilense, the Che1 chemotaxis pathway has a minor role in chemotaxis and root-surface colonization. However, the Che4 pathway regulates the swimming pattern of motile Azospirillum brasilense cells and wheat root-surface colonization. The Che 4 pathway is orthologous to the major pathway controlling all chemotaxis responses in Sinorhizobium meliloti (Armitage and Schmitt 1997) and Rhizobium leguminosarum (Caetano-Anollés et al. 1988), in which this chemotaxis system is also essential for plant root colonization. In this study, although the $\Delta c h e A$ and $\Delta c h e A-R$ mutants are not impaired in their absorption and nodulation ability after inoculation alone, all these mutants appeared to be severely impaired in their competitive colonization and nodulation behavior, suggesting that these genes positively control efficient nodulation, as also reported for IcpB and TlpA1. In contrast, CheZ was found to have a negative role (Liu et al. 2017b). In addition, the nonmotility $(\triangle f l i M)$ mutants were also severely defective in competitive nodule formation on roots and stems of the host plant. These results suggest that the chemotaxis signal transduction pathway controls flagella-driven motility, which regulates competitiveness in the rhizosphere.

In establishment of a successful symbiosis between rhizobia and legumes, in addition to chemotaxis and motility, bacterial surface lipopolysaccharides and EPS are essential for colonization and nodule development (Gao et al. 2001; Mathis et al. 2005; Mitra et al. 2016). The results reported here support the conclusion that the Che signaling pathway in A. caulinodans not only provide a competitive advantage in root colonization by regulating chemotaxis and mediating flagella-driven but also indirectly affected competitive colonization through affection biofilm formation or EPS biosynthesis.

\section{MATERIALS AND METHODS}

\section{Strains and growth condition.}

All strains and plasmids used in this study are listed in Table 1. A. caulinodans ORS571 wild-type strain and its derivatives were grown in L3 or tryptone yeast (TY) liquid medium at $37^{\circ} \mathrm{C}$ with shaking (180 rpm). The L3 medium is supplemented or not with $10 \mathrm{mM} \mathrm{NH}_{4} \mathrm{Cl}$. L3 and TY medium containing, per milliliter, $100 \mu \mathrm{g}$ of ampicillin and $25 \mu \mathrm{g}$ of nalidixic acid were prepared as described previously (Jiang et al. 2016a). E. coli was grown in $\mathrm{LB}$ medium or agar plates at $37^{\circ} \mathrm{C}$.

\section{Construction of mutants and complementation strain.}

To construct a marker-less che gene cluster deletion mutant (deletion of cheA, cheW, che $Y_{1}$, cheB, and cheR genes), a 825-bp upstream fragment (UF) was amplified by polymerase chain reaction (PCR) from the genomic DNA of A. caulinodans ORS571, using primers CheUF and CheUR (Table 2), and a 801-bp downstream fragment (DF) was amplified by PCR using primers CheDF and CheDR (Table 2). The PCR product corresponding to the upstream DNA fragment was digested with EcoRI-NdeI and was then inserted into the pCM351 plasmid (Marx and Lidstrom 2002) digested with EcoRI-NdeI. The resulting plasmid was designated as pCM351::UF. The PCR product corresponding to the DF was digested with SacIISacI and was cloned into pCM351::UF. The final plasmid, pCM351::UF::DF, was transformed into $E$. coli $\mathrm{DH} 5 \alpha$ and the DNA sequence was verified by sequencing, prior to mating. The recombinant plasmid was transferred into A. caulinodans ORS571 by triparental conjugation with the helper plasmid pRK2013 (Figurski and Helinski 1979). Recombinants from double homologous recombination were obtained and were screened on TY plates by selecting for gentamicin resistance and tetracycline sensitivity (Marx and Lidstrom, 2002). The potential mutant was generated by in-frame deletion of an internal 5,756-bp fragment and insertion of a gentamicin-resistance gene. The gentamicin gene was then deleted by introduction of the Cre expression plasmid pCM157 (Marx and Lidstrom 2002). The correct mutation was verified by PCR with primer pair CheAF and CheAR (Table 2), and a confirmed mutation was named $\Delta c h e A-R$.

To construct a complete deletion mutant of the cheA gene, a 501-bp UF was amplified using primer pair CheAUF and CheAUR (Table 2), and a 576-bp DF was amplified by PCR using primers CheADF and CheADR (Table 2). The PCR product of the upstream DNA fragment was digested with $\mathrm{Nsi}$ INdeI and was then inserted into the pCM351 plasmid digested with NsiI-NdeI. The resulting plasmid was termed pCM351:: UF. The PCR product corresponding to the DF was digested with ApaI-AgeI and was cloned into pCM351::UF. Plasmid pCM351::UF::DF was transformed into E. coli DH5 $\alpha$ and the DNA sequence was verified by sequencing. The recombinant plasmid was transferred into A. caulinodans ORS571 by triparental conjugation. The potential mutant was generated by in-frame deletion of an internal 2,793-bp fragment and insertion of a gentamicin-resistance gene. Then, the gentamicin gene was deleted by introduction of plasmid pCM157 (Marx and Lidstrom 2002). The introduction of the correct mutation was verified by PCR with primer pair CheAF and CheAR (Table 2), and a confirmed mutation was named $\Delta c h e A$.

For complementation of $\Delta c h e A$, the cheA ORF with $601 \mathrm{bp}$ immediately upstream from the noncoding sequence was amplified by PCR, using primer pair CheACF and CheACR (Table 2). The amplified 3,394-bp fragment was inserted into SpeI and XbaI sites of the broad host-range cloning vector pBBR1MCS-2

Table 1. Strains and plasmids used in this study

\begin{tabular}{|c|c|c|}
\hline Strain or plasmid & Relevant properties $^{\mathbf{a}}$ & Source or reference \\
\hline Azorhizobium caulinodans ORS571 & Wild-type strain, $\mathrm{Amp}^{\mathrm{r}}$, $\mathrm{Nal}^{\mathrm{r}}$ & Dreyfus et al. 1988 \\
\hline$\Delta c h e A-R$ & ORS571 derivative, che deletion mutant, $\mathrm{Amp}^{\mathrm{r}}, \mathrm{Nal}^{\mathrm{r}}$ & This study \\
\hline$\Delta c h e A$ & ORS571 derivative, cheA complete deletion mutant, $\mathrm{Amp}^{\mathrm{r}}, \mathrm{Nal}^{\mathrm{r}}$ & This study \\
\hline$\Delta f l i M$ & ORS571 derivative, $f l i M$ deletion mutant, $\mathrm{Amp}^{\mathrm{r}}, \mathrm{Nal}^{\mathrm{r}}$ & This study \\
\hline WT-pBBR & Wild type strain carrying pBBR1MCS-2, $\mathrm{Amp}^{\mathrm{r}}, \mathrm{Nal}^{\mathrm{r}}, \mathrm{Kan}^{\mathrm{r}}$ & This study \\
\hline$\Delta c h e A$-com & $\begin{array}{l}\text { ORS571 derivative, cheA deletion mutant carrying pBBR1MCS-2-cheA, } \\
\mathrm{Amp}^{\mathrm{r}}, \mathrm{Nal}^{\mathrm{r}}, \mathrm{Kan}^{\mathrm{r}}\end{array}$ & This study \\
\hline Escherichia coli DH5 $\alpha$ & 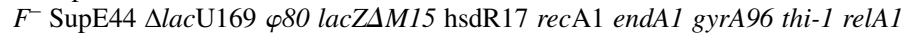 & Transgen \\
\hline pCM351 & Mobilizable allelic exchange vector, $\mathrm{Amp}^{\mathrm{r}}, \mathrm{Gen}^{\mathrm{r}}$ & Marx and Lidstrom 2002 \\
\hline pCM157 & IncP plasmid that expresses Cre recombinase, $\mathrm{Tet}^{\mathrm{r}}$ & Marx and Lidstrom 2002 \\
\hline pBBR1MCS-2 & Broad host-range plasmid, $\mathrm{Kan}^{\mathrm{r}}$ & Kovach et al. 1995 \\
\hline pBBR-cheA & pBBR1MCS-2 carrying the native promoter of the cheA and cheA gene, $\operatorname{Kan}^{\mathrm{r}}$ & This study \\
\hline pRK2013 & Helper plasmid, ColE1 replicon, $\mathrm{Tra}^{+}, \mathrm{Kan}^{\mathrm{r}}$ & Figurski and Helinski 1979 \\
\hline
\end{tabular}

${ }^{a} \mathrm{Amp}^{\mathrm{r}}, \mathrm{Nal}^{\mathrm{r}}, \mathrm{Gen}^{\mathrm{r}}, \mathrm{Kan}^{\mathrm{r}}$, and $\mathrm{Tet}^{\mathrm{r}}$ indicate ampicillin, nalidixic acid, gentamicin, kanamycin, and tetracycline resistance, respectively. 
(Kovach et al. 1995). The ligation mixture was transformed into $E$. coli DH5 $\alpha$. DNA sequences from individual clones were sequenced and one verified clone was designated as pBBR1MCS-2cheA-com. This recombinant plasmid, named pBBR-cheA, was then introduced into the $\triangle c h e A$ mutant via triparental mating and the transformants were recovered by selection for kanamycin resistance. One of the resulting strains was designated as $\Delta c h e A$-com.

To construct a fliM gene-deletion mutant, a 695-bp UF was amplified by PCR from the genomic DNA of $A$. caulinodans ORS571, using primer pair FliMUF and FliMUR (Table 2), and a 579-bp DF was amplified by PCR, using primers FliMDF and FliMDR (Table 2). The PCR product corresponding to the upstream DNA fragment was digested with KpnI-NdeI and was then inserted into the pCM351 plasmid digested with KpnINdeI. The resulting plasmid was termed as pCM351::UF. The PCR product corresponding to the DF was digested with AgeI-SacI and was cloned into pCM351::UF. A final plasmid, pCM351::UF:: DF, was transformed into E. coli $\mathrm{DH} 5 \alpha$ and the DNA sequence was verified by sequencing, prior to mating. The recombinant plasmid was transferred into $A$. caulinodans ORS571 by triparental conjugation. The potential mutant was generated by in-frame deletion of an internal 930-bp fragment and insertion of a gentamiciresistance gene. The gentamicin gene was then deleted (Marx and Lidstrom 2002). The mutation was verified by PCR with primer pair FliMF and FliMR (Table 2) and a confirmed mutation was named $\Delta$ fliM.

\section{Electron microscopy.}

Strains were grown overnight with shaking at $37^{\circ} \mathrm{C}$ in $\mathrm{TY}$ to mid-logarithmic phase. Cultures were inspected to ensure motility, and cells were taken directly from the cultures and adsorbed to Formvar-coated copper grids for $5 \mathrm{~min}$. Excess culture was blotted with filter paper and the grid was placed face down on a drop of $1 \%$ phosphotungstic acid for 1 min. Excess stain was blotted with filter paper, and the grid was dried. The images were obtained using a JEM-1400 electron microscope.

\section{Behavioral assays.}

Soft agar plates were used to detect chemotactic responses of the wild type and mutants to different carbon sources. L3 plates ( $0.35 \%$ agar) supplemented with $10 \mathrm{mM}$ carbon source (succinate, sodium lactate, or proline) as attractant and containing or not $10 \mathrm{mM} \mathrm{NH}_{4} \mathrm{Cl}$ as nitrogen source. Cells were grown up to mid-exponential phase in TY medium and were harvested by centrifugation. The cultures were washed twice and were then resuspended in the chemotaxis buffer $\left(10 \mathrm{mM} \mathrm{K}_{2} \mathrm{HPO}_{4}, 10 \mathrm{mM}\right.$ $\mathrm{KH}_{2} \mathrm{PO}_{4}, 0.1 \mathrm{mM}$ EDTA, $\mathrm{pH} 7.0$ ) to give an optical density at $600 \mathrm{~nm}\left(\mathrm{OD}_{600}\right)$ of 1.0. Aliquots of a 5 - $\mu$ l suspension were used to inoculate on L3 plates. The plates were incubated at $37^{\circ}$ for 48 to $72 \mathrm{~h}$ and, then, swimming diameters were recorded.

Quantitative capillary chemotaxis assays were performed as previously described by Reyes-Darias et al. (2016) with some minor modifications. The wild type and mutants were grown to early logarithmic phase $\left(\mathrm{OD}_{600}\right.$ of 0.3 to 0.4$)$ in TY medium. The cultures were washed and were resuspended with chemotaxis buffer to $\mathrm{OD}_{600}=0.05$. Then, 300- $\mu$ l aliquots of cell suspensions (1:1 ratio of wild-type to mutant) were added into each well of a 96-well plate. The open end of capillary tubes (containing $10 \mathrm{mM}$ succinate or sodium lactate as attractant) was placed into the wells. Capillary tubes filled with chemotaxis buffer were used as controls. Subsequently, the sealed end was broken and the contents were emptied into $1 \mathrm{ml}$ of sterile water, after incubation for $1 \mathrm{~h}$. Serial 10-fold dilutions were placed onto TY plates. Colonies $(n=480)$ randomly selected on TY plates were analyzed by PCR.

To observe the swimming behavior of cells, cultures were grown in TY medium to mid-exponential phase and the swimming behavior was observed and recorded using Olympus DP73 digital microscope camera. Videos were analyzed to

Table 2. Primers used in this study ${ }^{\mathrm{a}}$

\begin{tabular}{|c|c|c|}
\hline Primer & Sequence $\left(5^{\prime}-3^{\prime}\right)$ & Purpose \\
\hline CheUF-EcoRI & GGAATTCCGAGATCGGTACCCAGGTG & $\Delta c h e A-R$ mutant construction \\
\hline CheUR-NdeI & GGAATTCCATATGCTGTCACTCCAGCGGGCTG & $\Delta c h e A-R$ mutant construction \\
\hline CheDF-SacII & 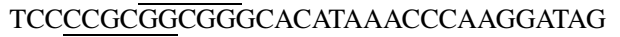 & $\Delta c h e A-R$ mutant construction \\
\hline CheDR-SacI & CGĀGCTCCGTCACGATGCTGCGGAAG & $\Delta c h e A-R$ mutant construction \\
\hline CheAF & CAGGAAGACTCCGAATACAAGGT & Validation of cheA or che \\
\hline CheAR & GATCATCTCGATGTTCGAGCG & Validation of cheA or che \\
\hline CheAUF-NsiI & ATGCATGGACACCATCCGCAAGATTGAC & $\Delta c h e A$ construction \\
\hline CheAUR-NdeI & CATATGCTCGCGCAGCAGATCATCCAT & $\Delta c h e A$ construction \\
\hline CheADF-ApaI & $\overline{\text { GGGCCCGCCCATGGAGAGGCGGCATGA }}$ & $\Delta c h e A$ construction \\
\hline CheADR-AgeI & ACCGGTCACCACGCCTGAATCATCCAC & $\Delta c h e A$ construction \\
\hline CheACF-SpeI & ACTAGTTGGCGAGCGAAGTGAAGTC & $\Delta c h e A$-com construction \\
\hline CheACR-XbaI & $\overline{\text { TCTAGA }}$ GTCGAACTTGGCGATGTAGTC & $\Delta c h e A$-com construction \\
\hline FliMUF-KpnI & $\overline{\text { GGTACC CGACCGAGCTTCATGAGAT }}$ & $\Delta f l i M$ construction \\
\hline FliMUR-NdeI & CATATGGCGGGTCGAAGAGCAGATC & $\Delta f l i M$ construction \\
\hline FliMDF-AgeI & ACCGGTCATCGAGCAGCATGTCT & $\Delta f l i M$ construction \\
\hline FliMDR-SacI & GAGCTCGACGCAGTATATCTGCGAC & $\Delta f l i M$ construction \\
\hline FliMF & 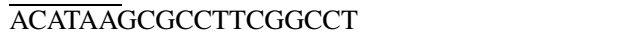 & Validation of fliM \\
\hline FliMR & GTCATCTTCGACCGCCTGG & Validation of fliM \\
\hline CheAQF & GTCTCGTGGTGGACGAGATT & RT-PCR for $c h e A$ \\
\hline CheAQR & TGAGGTTGCGGTAGAAGAGG & RT-PCR for $c h e A$ \\
\hline CheWQF & GTCTTCGTACCGGACCACAT & RT-PCR for cheW \\
\hline CheWQR & ACCTCGTCGATCATCAGTCC & RT-PCR for cheW \\
\hline $\mathrm{CheY}_{1} \mathrm{QF}$ & CCGACTGGAACATGGAGCCGAT & RT-PCR for $c h e Y_{1}$ \\
\hline $\mathrm{CheY}_{1} \mathrm{QR}$ & TCAGGCCTCGAACACGGTGTC & RT-PCR for $c h e Y_{1}$ \\
\hline CheBQF & ACATGGTGCTGGAGAAGTCC & RT-PCR for $c h e B$ \\
\hline CheBQR & AACGACGCTTGTTTCTTCGT & RT-PCR for $c h e B$ \\
\hline CheRQF & CGCTGGCGATGACGCTGAAG & RT-PCR for $c h e R$ \\
\hline CheRQR & AGGCCCACGAACGGGTTGAG & RT-PCR for $c h e R$ \\
\hline $16 \mathrm{SQF}$ & ACGGATTTCTTCCAGCAATG & RT-PCR for $16 S r R N A$ \\
\hline 16SQR & ACCGGCAGTCCCTTTAGAGT & RT-PCR for $16 S r R N A$ \\
\hline
\end{tabular}

\footnotetext{
${ }^{\text {a }}$ Engineered restriction sites are underlined; RT-PCR = reverse transcription-polymerase chain reaction.
} 
observe the cell paths for 2 to $3 \mathrm{~s}$. For each strain, at least five independent experiments were observed.

\section{Reverse transcription PCR.}

Total RNA was isolated from cultured free-living cells of wild type and mutants. cDNA was generated using the TransScript all-in-one first-strand cDNA synthesis supermix for quantitative PCR (one-step genomic DNA removal) kit (Transgen) and was diluted fivefold as template for subsequent PCR amplification. PCR was performed with gene-specific primer pairs (Table 2). The PCR program included an initial denaturation step at $95^{\circ} \mathrm{C}$ for $3 \mathrm{~min}$, followed by 30 cycles of $95^{\circ} \mathrm{C}$ for $30 \mathrm{~s}, 62^{\circ} \mathrm{C}$ for $30 \mathrm{~s}$, and $72^{\circ} \mathrm{C}$ for $30 \mathrm{~s}$.

\section{Biofilm assays.}

To form biofilm on abiotic surfaces (glass tubes), cell cultures $\left(\mathrm{OD}_{600}\right.$ of 2.5) were resuspended in L3 medium. Cultures $(150 \mu \mathrm{l})$ were inoculated into $1.5-\mathrm{ml}$ glass tubes at $37^{\circ} \mathrm{C}$ for 3 to 5 days. For crystal violet staining, cultures were removed and were washed with double-distilled $(\mathrm{dd}) \mathrm{H}_{2} \mathrm{O}$ three to five times. Then, $0.5 \%$ crystal violet was added into each tube. After incubation for 20 min, the crystal violet was removed and was washed with $\mathrm{ddH}_{2} \mathrm{O}$ five times, the water was removed completely in the final wash, and $1.5 \mathrm{ml}$ of $30 \%$ acetic acid was added to dissolve the "crystal violet ring" off and the $\mathrm{OD}_{570}$ was determined.

\section{EPS production assay.}

For the examination of EPS production, overnight cultures were adjusted to an $\mathrm{OD}_{600}$ of 1.0 , and $15 \mu \mathrm{l}$ of bacterial suspension was inoculated onto solid L3 plates $(0.8 \%$ agar) and was then incubated at $37^{\circ} \mathrm{C}$ for 1 to 3 days. L3 plates contained $10 \mathrm{mM}$ of different carbon sources and were supplemented or not with $10 \mathrm{mM} \mathrm{NH}_{4} \mathrm{Cl}$ as the nitrogen source. Quantification of EPS production was performed based on the method of Nakajima et al. (2012), with some minor modifications. Bacteria on the L3 plates were collected and were resuspended in $\lambda$-buffer (10 mM Tris- $\left.\mathrm{HCl}, \mathrm{pH} 7.0,10 \mathrm{mM} \mathrm{MgSO}{ }_{4}\right)$. Supernatant containing the EPS soluble fraction were first treated with $1 \mathrm{ml}$ of concentrated sulfuric acid containing $0.2 \%$ anthrone, mixed, and incubated for $7 \mathrm{~min}$ at $100^{\circ} \mathrm{C}$, and then, were quickly chilled on ice. The $\mathrm{OD}_{620}$ of the mixture was measured on a Nanodrop 2000C. D-glucose was used for the standard curve.

\section{Adsorption and colonization assay of roots.}

The number of root-adsorbed rhizobia was determined as described by Zamudio and Bastarrachea (1994), with some minor modifications. S. rostrata seeds were germinated and grown under sterile conditions for 3 days. Cultures of each strain $\left(\mathrm{OD}_{600} \mathrm{~nm}\right.$ of 0.2$)$ were used to inoculate seedlings for $4 \mathrm{~h}$ at $28^{\circ} \mathrm{C}$, with slow shaking, at $50 \mathrm{rpm}$. The slow shaking was included to reduce the likelihood that motility differences account for differences in reaching the root surfaces. Then, the seedlings were washed by gentle suspension with sterile water shaking in the rotary bath at $100 \mathrm{rpm}$ for $1 \mathrm{~min}$. Five consecutive washes were performed to remove the excess bacteria. The terminal $2 \mathrm{~cm}$ of the inoculated roots of five plants were dispersed in sterile water by a homogenizer and the dilution was spread on TY agar plates. The adsorption pattern of the root surfaces was examined by counting the colony-forming units on TY agar plates. In the competitive adsorption experiment, surface-sterilized seedlings were inoculated with mixtures of wild type and mutants at approximate $1: 1$ for $4 \mathrm{~h}$.

Colonization assays were carried out as described by GreerPhillips et al. (2004), with a few modifications. Wild type and mutants were mixed $1: 1$ and were added to glass bottles containing $200 \mathrm{ml}$ of molten agar $(0.35 \%$ agar $)$. Ten surfacesterilized seedlings were embedded into each bottle and were incubated at $30^{\circ} \mathrm{C}$. After 7 days, the roots were washed and were homogenized by homogenizer. Serial dilutions of the supernatant were spread on TY agar plates to count colony-forming units. Colonies were further assigned as detected by PCR. A noninoculated control flask was included for all experiments.

\section{Nodulation assays.}

Nodulation and competition assays were carried out as described by Yost et al. (1998), with the following modifications. For nodulation assays on roots, surface-sterilized seedlings were co-inoculated with each strain in an approximate $\mathrm{OD}_{600}$ of 0.5 . For stem nodulation assays, stems root primordial were inoculated with the bacterial suspension by painting using sterile cotton wool. For competitive nodulation assays on roots and stems, surface-sterilized seedlings and plant stems were coinoculated with wild type and mutants in an approximate 1:1 ratio. All plants were grown at $27^{\circ} \mathrm{C}$ in the greenhouse, with a daylight illumination period of $12 \mathrm{~h}$. Stem nodules were harvested 20 to 30 days postinoculation. Bacteria were re-isolated from surface-sterilized nodules and colonies were identified by PCR. Controls included uninoculated plants.

\section{ACKNOWLEDGMENTS}

We thank T. Aono, S. Li, and Z. Zhong for kindly providing A. caulinodans ORS571, S. rostrata seeds. We thank M. E. Lidstrom for kindly providing pCM351 and pCM157 plasmids

\section{LITERATURE CITED}

Armitage, J. P., and Schmitt, R. 1997. Bacterial chemotaxis: Rhodobacter sphaeroides and Sinorhizobium meliloti-Variations on a theme? Microbiology 143:3671-3682.

Berleman, J. E., and Bauer, C. E. 2005. Involvement of a Che-like signal transduction cascade in regulating cyst cell development in Rhodospirillum centenum. Mol. Microbiol. 56:1457-1466.

Bernabéu-Roda, L., Calatrava-Morales, N., Cuéllar, V., and Soto, M. J. 2015. Characterization of surface motility in Sinorhizobium meliloti: Regulation and role in symbiosis. Symbiosis 67:79-90.

Bianciotto, V., Andreotti, S., Balestrini, R., Bonfante, P., and Perotto, S. 2001. Mucoid mutants of the biocontrol strain Pseudomonas fluorescens CHA0 show increased ability in biofilm formation on mycorrhizal and nonmycorrhizal carrot roots. Mol. Plant-Microbe Interact. 14: 255-260.

Bible, A., Russell, M. H., and Alexandre, G. 2012. The Azospirillum brasilense $\mathrm{Che} 1$ chemotaxis pathway controls swimming velocity, which affects transient cell-to-cell clumping. J. Bacteriol. 194:3343-3355.

Bible, A. N., Stephens, B. B., Ortega, D. R., Xie, Z., and Alexandre, G. 2008. Function of a chemotaxis-like signal transduction pathway in modulating motility, cell clumping, and cell length in the alphaproteobacterium Azospirillum brasilense. J. Bacteriol. 190:6365-6375.

Brencic, A., and Winans, S. C. 2005. Detection of and response to signals involved in host-microbe interactions by plant-associated bacteria Microbiol. Mol. Biol. Rev. 69:155-194.

Burdman, S., Okon, Y., and Jurkevitch, E. 2000. Surface characteristics of Azospirillum brasilense in relation to cell aggregation and attachment to plant roots. Crit. Rev. Microbiol. 26:91-110.

Caetano-Anollés, G., Wall, L. G., De Micheli, A. T., Macchi, E. M., Bauer, W. D., and Favelukes, G. 1988. Role of motility and chemotaxis in efficiency of nodulation by Rhizobium meliloti. Plant Physiol. 86:1228-1235.

Cheng, H. P., and Walker, G. C. 1998. Succinoglycan is required for initiation and elongation of infection threads during nodulation of alfalfa by Rhizobium meliloti. J. Bacteriol. 180:5183-5191.

D’Argenio, D. A., Calfee, M. W., Rainey, P. B., and Pesci, E. C. 2002. Autolysis and autoaggregation in Pseudomonas aeruginosa colony morphology mutants. J. Bacteriol. 184:6481-6489.

de Weger, L. A., Kuiper, I., van der Bij, A. J., and Lugtenberg, B. J. J. 1997 Use of a lux-based procedure to rapidly visualize root colonisation by Pseudomonas fluorescens in the wheat rhizosphere. Antonie van Leeuwenhoek 72:365-372.

Dekkers, L. C., Bloemendaal, C. J., de Weger, L. A., Wijffelman, C. A., Spaink, H. P., and Lugtenberg, B. J. 1998. A two-component system 
plays an important role in the root-colonizing ability of Pseudomonas fluorescens strain WCS365. Mol. Plant-Microbe Interact. 11:45-56.

Doherty, D., Leigh, J. A., Glazebrook, J., and Walker, G. C. 1988. Rhizobium meliloti mutants that overproduce the $R$. meliloti acidic calcofluor-binding exopolysaccharide. J. Bacteriol. 170:4249-4256.

Dreyfus, B., Garcia, J. L., and Gillis, M. 1988. Characterization of Azorhizobium caulinodans gen. nov., sp.nov., a stem-nodulating nitrogen-fixing bacterium isolated from Sesbania rostrata. Int. J. Syst. Bacteriol. 38:633-639.

Dreyfus, B. L., Elmerich, C., and Dommergues, Y. R. 1983. Free-living Rhizobium strain able to grow on $\mathrm{N}_{2}$ as the sole nitrogen source. Appl. Environ. Microbiol. 45:711-713.

Ferrández, A., Hawkins, A. C., Summerfield, D. T., and Harwood, C. S. 2002. Cluster II che genes from Pseudomonas aeruginosa are required for an optimal chemotactic response. J. Bacteriol. 184:4374-4383.

Figurski, D. H., and Helinski, D. R. 1979. Replication of an origincontaining derivative of plasmid $\mathrm{RK}_{2}$ dependent on a plasmid function provided in trans. Proc. Natl. Acad. Sci. U.S.A. 76:1648-1652.

Fraysse, N., Couderc, F., and Poinsot, V. 2003. Surface polysaccharide involvement in establishing the rhizobium-legume symbiosis. Eur. J. Biochem. 270:1365-1380.

Fujishige, N. A., Kapadia, N. N., De Hoff, P. L., and Hirsch, A. M. 2006. Investigations of Rhizobium biofilm formation. FEMS Microbiol. Ecol. 56:195-206.

Gao, M., D'Haeze, W., De Rycke, R., Wolucka, B., and Holsters, M. 2001. Knockout of an azorhizobial dTDP-L-rhamnose synthase affects lipopolysaccharide and extracellular polysaccharide production and disables symbiosis with Sesbania rostrata. Mol. Plant-Microbe Interact. 14:857-866.

Greer-Phillips, S. E., Stephens, B. B., and Alexandre, G. 2004. An energy taxis transducer promotes root colonization by Azospirillum brasilense. J. Bacteriol. 186:6595-6604.

Gullett, J. M., Bible, A., and Alexandre, G. 2017. Distinct Domains of CheA Confer Unique Functions in Chemotaxis and Cell Length in Azospirillum brasilense Sp7. J. Bacteriol. 199:e00189-17.

James, E. K., Loureiro, M. D. F., Pott, A., Pott, V. J., Martins, C. M., Franco, A. A., and Sprent, J. I. 2001. Flooding-tolerant legume symbioses from the Brazilian Pantanal. New Phytol. 150:723-738.

Jiang, N., Liu, W., Li, Y., Wu, H., Zhang, Z., Alexandre, G., Elmerich, C., and Xie, Z. 2016a. A chemotaxis receptor modulates nodulation during the Azorhizobium caulinodans-Sesbania rostrata symbiosis. Appl. Environ. Microbiol. 82:3174-3184.

Jiang, N., Liu, W., Li, Y., and Xie, Z. H. 2016b. Comparative genomic and protein sequence analyses of the chemotaxis system of Azorhizobium caulinodans. Acta Microbiol. Sin. 56:1256-1265.

Kirby, J. R., and Zusman, D. R. 2003. Chemosensory regulation of developmental gene expression in Myxococcus xanthus. Proc. Natl. Acad. Sci. U.S.A. 100:2008-2013.

Kovach, M. E., Elzer, P. H., Hill, D. S., Robertson, G. T., Farris, M. A., Roop, R. M., 2nd, and Peterson, K. M. 1995. Four new derivatives of the broad-host-range cloning vector pBBR1MCS, carrying different antibiotic-resistance cassettes. Gene 166:175-176.

Lee, K. B., De Backer, P., Aono, T., Liu, C. T., Suzuki, S., Suzuki, T., Kaneko, T., Yamada, M., Tabata, S., Kupfer, D. M., Najar, F. Z., Wiley, G. B., Roe, B., Binnewies, T. T., Ussery, D. W., D’Haeze, W., Herder, J. D., Gevers, D., Vereecke, D., Holsters, M., and Oyaizu, H. 2008. The genome of the versatile nitrogen fixer Azorhizobium caulinodans ORS571. BMC Genomics 9:271-284.

Liu, W., Yang, J., Sun, Y., Liu, X., Li, Y., Zhang, Z., and Xie, Z. 2017a. Azorhizobium caulinodans transmembrane chemoreceptor TlpA1 involved in host colonization and nodulation on roots and stems. Front. Microbiol. 8:1327.

Liu, X. L., Liu, W., Sun, Y., Xia, C. L., Elmerich, C., and Xie, Z. H. 2017b. A cheZ-like gene in Azorhizobium caulinodans is a key gene in the control of chemotaxis and colonization of the host plant. Appl. Environ. Microbiol. 84:e01827-17.

Marx, C. J., and Lidstrom, M. E. 2002. Broad-host-range cre-lox system for antibiotic marker recycling in gram-negative bacteria. Biotechniques 33:1062-1067.

Mathis, R., Van Gijsegem, F., De Rycke, R., D’Haeze, W., Van Maelsaeke, E., Anthonio, E., Van Montagu, M., Holsters, M., and Vereecke, D. 2005. Lipopolysaccharides as a communication signal for progression of legume endosymbiosis. Proc. Natl. Acad. Sci. U.S.A. 102:2655-2660.

Matthysse, A. G., Marry, M., Krall, L., Kaye, M., Ramey, B. E., Fuqua, C., and White, A. R. 2005. The effect of cellulose overproduction on binding and biofilm formation on roots by Agrobacterium tumefaciens. Mol. Plant-Microbe Interact. 18:1002-1010.

Meier, V. M., Muschler, P., and Scharf, B. E. 2007. Functional analysis of nine putative chemoreceptor proteins in Sinorhizobium meliloti. J. Bacteriol. 189:1816-1826.
Meneses, C. H., Rouws, L. F., Simões-Araújo, J. L., Vidal, M. S., and Baldani, J. I. 2011. Exopolysaccharide production is required for biofilm formation and plant colonization by the nitrogen-fixing endophyte Gluconacetobacter diazotrophicus. Mol. Plant-Microbe Interact. 24: 1448-1458

Merritt, P. M., Danhorn, T., and Fuqua, C. 2007. Motility and chemotaxis in Agrobacterium tumefaciens surface attachment and biofilm formation. J. Bacteriol. 189:8005-8014.

Michiels, K. W., Croes, C. L., and Vanderleyden, J. 1991. Two different modes of attachment of Azospirillum brasilense $\mathrm{Sp} 7$ to wheat roots. J. Gen. Microbiol. 137:2241-2246.

Miller, L. D., Yost, C. K., Hynes, M. F., and Alexandre, G. 2007. The major chemotaxis gene cluster of Rhizobium leguminosarum bv. viciae is essential for competitive nodulation. Mol. Microbiol. 63:348-362.

Mitra, S., Mukherjee, A., Wiley-Kalil, A., Das, S., Owen, H., Reddy, P. M., Ané, J. M., James, E. K., and Gyaneshwar, P. 2016. A rhamnose-deficient lipopolysaccharide mutant of Rhizobium sp. IRBG74 is defective in root colonization and beneficial interactions with its flooding-tolerant hosts Sesbania cannabina and wetland rice. J. Exp. Bot. 67:5869-5884.

Mukherjee, T., Kumar, D., Burriss, N., Xie, Z., and Alexandre, G. 2016. Azospirillum brasilense chemotaxis depends on two signaling pathways regulating distinct motility parameters. J. Bacteriol. 198:1764-1772.

Nakajima, A., Aono, T., Tsukada, S., Siarot, L., Ogawa, T., and Oyaizu, H. 2012. Lon protease of Azorhizobium caulinodans ORS571 is required for suppression of $r e b$ gene expression. Appl. Environ. Microbiol. 78: 6251-6261.

Pratt, L. A., and Kolter, R. 1998. Genetic analysis of Escherichia coli biofilm formation: Roles of flagella, motility, chemotaxis and type I pili. Mol. Microbiol. 30:285-293.

Ramey, B. E., Koutsoudis, M., von Bodman, S. B., and Fuqua, C. 2004 Biofilm formation in plant-microbe associations. Curr. Opin. Microbiol. 7:602-609.

Reyes-Darias, J. A., García, V., Rico-Jiménez, M., Corral-Lugo, A., and Krell, T. 2016. Identification and characterization of bacterial chemoreceptors using quantitative capillary and gradient plate chemotaxis assays. Bio Protoc. 6:e1789.

Rinaudi, L. V., and Giordano, W. 2010. An integrated view of biofilm formation in rhizobia. FEMS Microbiol. Lett. 304:1-11.

Ryder, C., Byrd, M., and Wozniak, D. J. 2007. Role of polysaccharides in Pseudomonas aeruginosa biofilm development. Curr. Opin. Microbiol. 10:644-648.

Santaella, C., Schue, M., Berge, O., Heulin, T., and Achouak, W. 2008. The exopolysaccharide of Rhizobium sp. YAS34 is not necessary for biofilm formation on Arabidopsis thaliana and Brassica napus roots but contributes to root colonization. Environ. Microbiol. 10:2150-2163.

Scharf, B. E., Hynes, M. F., and Alexandre, G. M. 2016. Chemotaxis signaling systems in model beneficial plant-bacteria associations. Plant Mol. Biol. 90:549-559.

Simons, M., van der Bij, A. J., Brand, I., de Weger, L. A., Wijffelman, C. A., and Lugtenberg, B. J. J. 1996. Gnotobiotic system for studying rhizosphere colonization by plant growth-promoting Pseudomonas bacteria. Mol. Plant-Microbe Interact. 9:600-607.

Siuti, P., Green, C., Edwards, A. N., Doktycz, M. J., and Alexandre, G. 2011. The chemotaxis-like Che1 pathway has an indirect role in adhesive cell properties of Azospirillum brasilense. FEMS Microbiol. Lett. 323: 105-112.

Skorupska, A., Janczarek, M., Marczak, M., Mazur, A., and Król, J. 2006. Rhizobial exopolysaccharides: Genetic control and symbiotic functions. Microb. Cell Fact. 5:7.

Sourjik, V., and Schmitt, R. 1996. Different roles of CheY1 and CheY2 in the chemotaxis of Rhizobium meliloti. Mol. Microbiol. 22:427-436.

Stock, J. B., and Surette, M. G. 1996. Chemotaxis. Pages 1103-1129 in: Escherichia coli and Salmonella typhimurium: Molecular and Cellular Biology. F. C. Neidhardt, ed. Vol. 1. American Society for Microbiology, Washington, DC.

Szurmant, H., and Ordal, G. W. 2004. Diversity in chemotaxis mechanisms among the bacteria and archaea. Microbiol. Mol. Biol. Rev. 68: 301-319.

Tsien, H. C., Dreyfus, B. L., and Schmidt, E. L. 1983. Initial stages in the morphogenesis of nitrogen-fixing stem nodules of Sesbania rostrata. J. Bacteriol. 156:888-897.

Van de Broek, A., Lambrecht, M., and Vanderleyden, J. 1998. Bacterial chemotactic motility is important for the initiation of wheat root colonization by Azospirillum brasilense. Microbiology 144: 2599-2606.

Van de Broek, A., and Vanderleyden, J. 1995. The role of bacterial motility, chemotaxis, and attachment in bacteria-plant interactions. Mol. PlantMicrobe Interact. 8:800-810. 
Vlamakis, H. C., Kirby, J. R., and Zusman, D. R. 2004. The Che4 pathway of Myxococcus xanthus regulates type IV pilus-mediated motility. Mol. Microbiol. 52:1799-1811.

Wadhams, G. H., and Armitage, J. P. 2004. Making sense of it all: Bacterial chemotaxis. Nat. Rev. Mol. Cell Biol. 5:1024-1037.

Watnick, P., and Kolter, R. 2000. Biofilm, city of microbes. J. Bacteriol. 182:2675-2679.

Wells, D. H., Chen, E. J., Fisher, R. F., and Long, S. R. 2007. ExoR is genetically coupled to the ExoS-ChvI two-component system and located in the periplasm of Sinorhizobium meliloti. Mol. Microbiol. 64: 647-664.

Wisniewski-Dyé, F., Borziak, K., Khalsa-Moyers, G., Alexandre, G., Sukharnikov, L. O., Wuichet, K., Hurst, G. B., McDonald, W. H. Robertson, J. S., Barbe, V., Calteau, A., Rouy, Z., Mangenot, S., PrigentCombaret, C., Normand, P., Boyer, M., Siguier, P., Dessaux, Y., Elmerich, C., Condemine, G., Krishnen, G., Kennedy, I., Paterson, A. H.,
González, V., Mavingui, P., and Zhulin, I. B. 2011. Azospirillum genomes reveal transition of bacteria from aquatic to terrestrial environments. PLoS Genet. 7:e1002430.

Wuichet, K., and Zhulin, I. B. 2010. Origins and diversification of a complex signal transduction system in prokaryotes. Sci. Signal. 3:ra50.

Yaryura, P. M., León, M., Correa, O. S., Kerber, N. L., Pucheu, N. L., and García, A. F. 2008. Assessment of the role of chemotaxis and biofilm formation as requirements for colonization of roots and seeds of soybean plants by Bacillus amyloliquefaciens BNM339. Curr. Microbiol. 56:625-632.

Yost, C. K., Rochepeau, P., and Hynes, M. F. 1998. Rhizobium leguminosarum contains a group of genes that appear to code for methyl-accepting chemotaxis proteins. Microbiology 144:1945-1956.

Zamudio, M., and Bastarrachea, F. 1994. Adhesiveness and root hair deformation capacity of Azospirillum strains for wheat seedlings. Soil Biol. Biochem. 26:791-797. 